\title{
Idaho National Laboratory Integrated Safety Management System 2011 Effectiveness Review and Declaration Report
}

December 2011

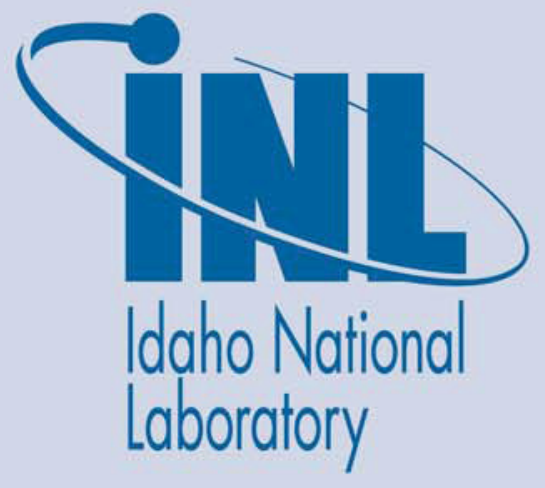

The INL is a U.S. Department of Energy National Laboratory operated by Battelle Energy Alliance 


\section{DISCLAIMER}

This information was prepared as an account of work sponsored by an agency of the U.S. Government. Neither the U.S. Government nor any agency thereof, nor any of their employees, makes any warranty, expressed or implied, or assumes any legal liability or responsibility for the accuracy, completeness, or usefulness, of any information, apparatus, product, or process disclosed, or represents that its use would not infringe privately owned rights. References herein to any specific commercial product, process, or service by trade name, trade mark, manufacturer, or otherwise, does not necessarily constitute or imply its endorsement, recommendation, or favoring by the U.S. Government or any agency thereof. The views and opinions of authors expressed herein do not necessarily state or reflect those of the U.S. Government or any agency thereof. 


\section{Idaho National Laboratory Integrated Safety Management System 2011 Effectiveness Review and Declaration Report}

December 2011

Idaho National Laboratory Idaho Falls, Idaho 83415

http://www.inl.gov

Prepared for the

U.S. Department of Energy

Under DOE Idaho Operations Office

Contract DE-AC07-05ID14517 
INTENTIONALLY BLANK 


\section{Idaho National Laboratory Integrated Safety Management System 2011 Effectiveness Review and Declaration Report}

INL/EXT11-23874

December 2011

Approved by:

Farren Hunt

Date

Integrated Safety Management Program Manager

Sharon Dossett

Environmental Safety \& Health Director

Date

Carlo Melbihess

Date

Operations Council Chairman 
INTENTIONALLY BLANK 


\section{EXECUTIVE SUMMARY}

Idaho National Laboratory (INL) performed an annual Integrated Safety Management System (ISMS) effectiveness review per 48 Code of Federal Regulations (CFR) 970.5223-1, "Integration of Environment, Safety and Health into Work Planning and Execution." The annual review assessed Integrated Safety Management (ISM) effectiveness, provided feedback to maintain system integrity, and helped identify target areas for focused improvements and assessments for fiscal year (FY) 2012. The information presented in this review of FY 2011 shows that the INL has performed many corrective actions and improvement activities, which are starting to show some of the desired results. These corrective actions and improvement activities will continue to help change culture that will lead to better implementation of defined programs, resulting in moving the Laboratory's performance from the categorization of "Needs Improvement" to the desired results of "Effective Performance."

This evaluation of ISM, based on performance data between October 1, 2010, and September 30, 2011, identified strengths and opportunities for improvement, and led to the following overall conclusions about the status and effectiveness of the INL ISMS.

All ISM elements have been maintained and many have been improved. The ISM processes have been functioning properly. No elements of the system were identified as having degraded during the year and a number of key improvements have been implemented to address issues with application of some ISM processes.

The system is effective for performing work safely. The INL ISMS continues to be a well-designed program focused on continuous improvement that provides a foundation to ensure work is accomplished in a manner that protects workers, the public, and environment. INL revised the annual effectiveness determination for FY 2010, using one of the three Department of Energy (DOE) descriptors in DOE M 450.4-1 "Integrated Safety Management System Manual," to "Needs Improvement - ISM is being effectively implemented, but noteworthy weaknesses need to be addressed."

It was identified that significant improvements to INL's work control processes were needed.

Key corrective actions and initiatives that began in FY 2011 and continuing into FY 2012 to correct these weaknesses are having the intended effect. INL continues to have some isolated events that indicate improvements have not been in place long enough to achieve the desired outcomes or that the actions taken were either the wrong actions or ineffective. Continued surveillance and dedicated resources have been a main priority to ensure that success will follow. These actions implemented by INL demonstrate that the overall Integrated Safety Management System as a whole is sound and ensures safe and successful performance of work as demonstrated by significant work accomplishments in FY 2011. ISM Program effectiveness is also substantiated by a number of indicators, performance analyses, data trending, work accomplishments, and assessment results.

Opportunities for improvement have been identified. Significant improvement opportunities were identified for INL's radiological work and work control processes. Key corrective actions and initiatives were put into place in FY 2011 to correct these weaknesses and drive sustained improvements in radiological work, work control, and operations. Corporate resources were leveraged via the BEA Board and INL Operations Committee. INL and DOE assessments performed in FY 2011 have confirmed that the actions taken have driven immediate improvement, and are having the intended effect of long-term sustainable improvement.

INL feedback and improvement processes also identified weaknesses in work planning, work control, and in-field supervision. Expectations for adhering to procedure requirements were not being consistently reinforced by line management, which sometimes caused risk to be managed at too low a level within some organizations. Corrective actions for this were incorporated into a comprehensive sitewide plan 
(PLN-3762“INL Work Control Corrective Action Plan") and are substantially complete. These assessments and event data indicate that the actions from PLN-3762 and previous action plans such as PLN-3763 ("MFC Recovery Plan") have produced positive results, but have not completely eliminated incidents; for example, there have been events such as the recent radiation exposure incident at Materials and Fuels Complex (MFC), the burn from an unfocused laser beam at Specific Manufacturing Capability (SMC) and inadequate pre-operational cooling supply valve line up checks at the Neutron Radiography Reactor (NRAD). In addition to continuing efforts to complete the actions of PLN-3762, which are focused primarily on maturing and sustaining the initial actions, INL management has kicked off a "sustained operational improvement" initiative to leverage the success of these plans and drive continual improvement, with the ultimate goal of establishing lasting operational excellence at the Laboratory. This long-term initiative began early in FY 2012 and has aggressive goals for significant sustained improvement.

Opportunities to improve INL training programs and strengthen the ISMS principle of Competence Commensurate with Responsibility were also identified early in FY 2011, resulting in a new training organization that has been stood up with new management establishing training standards and expectations to strengthen this principle at the INL.

Battelle Energy Alliance, LLC, strongly supports ISMS functions and principles and is committed to continual improvement. The BEA Board and Operations Committee fully support ISMS as evidenced by the corporate resources they provided over FY 2011 to ensure effectiveness of ISMS. All work at INL is managed by processes and procedures that implement the ISMS five core functions and eight guiding principles. INL leaders and workers demonstrate a strong, genuine, continual, and personal commitment to ISMS elements at the laboratory, facility, and activity level. Keys to success of achieving a breakthrough in reducing safety incidents and improving work planning and control reside in the continual improvement and maturation of the contractor assurance system and continued emphasis by INL leadership. The purpose of this review is to evaluate the major "evidence" from assessments, focus on specific issues, and evaluate overall performance while providing a summary of strengths, weaknesses, ongoing improvement initiatives, and additional opportunities for improvement as they relate to ISMS.

The effectiveness review resulted in no additional issues that weren't already identified and addressed as described in this report, six Observations, and two Recommendations.

\section{Overall Performance Rating -Needs Improvement}




\section{CONTENTS}

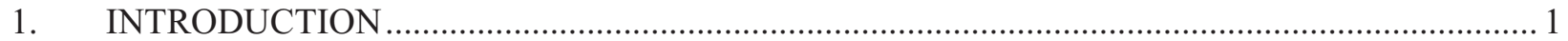

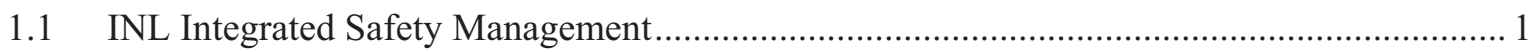

1.1.1 Guiding Principles and Core Functions of ISM at INL …................................. 1

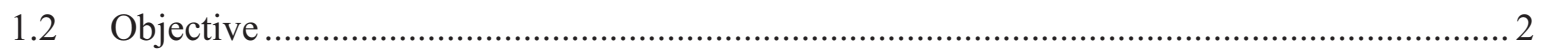

1.3 Areas of Concern from 2010 Effectiveness Review and Declaration...................................2

1.4 Summary of Major Actions and Initiatives to Address Areas of Concern from 2010 Effectiveness Review and Declaration................................................................................. 4

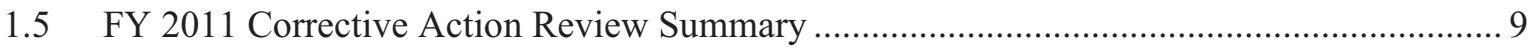

2. ISMS SAFETY PERFORMANCE OBJECTIVES, PERFORMANCE

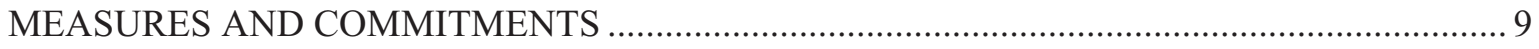

2.1 Status and Summary of FY 2011 Measures .................................................................... 10

2.2 Status and Summary of FY 2011 Safety Performance Commitments ................................ 13

2.3 FY 2012 Safety Performance Objectives and Commitments................................................ 14

2.4 FY 2012 Safety Performance Measures............................................................................ 14

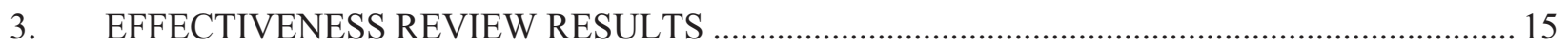

\section{FIGURES}

Figure A-1. Assurance activities and ICAMS issues summary for FY 2011 ....................................... 28

Figure A-2. Corrective actions by assessment type and guiding principle..............................................33

Figure A-3. Corrective actions by assessment type and core function. ................................................. 34

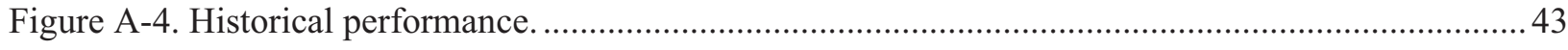

Figure A-5. Quarterly number of occurrence reports by quarter for the last 2 years.............................50

\section{TABLES}

Table 1. Proactively identified issues. .11

Table 2. Origin of issues by organization function and/or activity. 11

Table A-3. Assessment activities for the applicable eight guiding principles and five core functions. 29

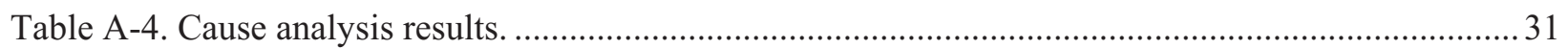

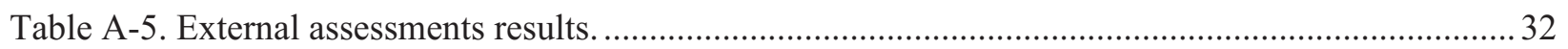

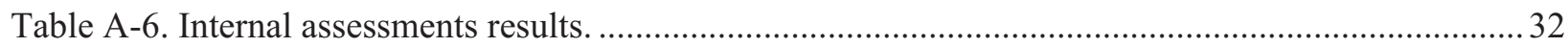

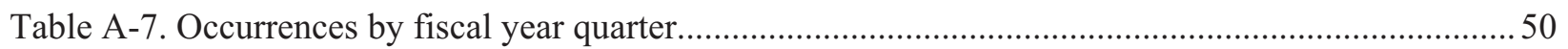

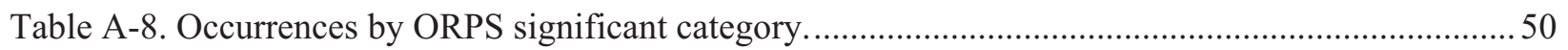


INTENTIONALLY BLANK 


\section{ACRONYMS}

AEB Assessment Evaluation Board

AED automated external defibrillator

ATR Advanced Test Reactor

BOC Battelle Energy Alliance Operations Committee

BEA Battelle Energy Alliance, LLC

CAP Corrective Action Plan

CARB Corrective Action Review Board

CAS Contractor Assurance System

CCR Competence Commensurate with Responsibilities

CFA Central Facilities Area

CFR Code of Federal Regulations

$\mathrm{CP} \quad$ civil penalty

CWI CH2M-WG Idaho, LLC

CY calendar year

DART day away, restricted or transferred

DEAR DOE Acquisition Regulation

DEQ Department of Environmental Quality

DOE Department of Energy

DOE-HSS Office of Health, Safety and Security Office of Enforcement and Oversight

DOE-ID Department of Energy Idaho Operations Office

EDMS Electronic Document Management System

EFCOG Energy Facility Contractors Group

EMS Environmental Management System

ES\&H Environment, Safety, and Health

ESI Electrical Severity Index

EST Employee Safety Team

F\&SS Facilities and Site Services

FCF Fuel Conditioning Facility

FEC Federal Electronics Challenge

FNOV Final Notice of Violation

FY fiscal year

FYTD fiscal year to date

HFEF Hot Fuel Examination Facility 
HPI Human Performance Improvement

HPIL Health Physics Instrumentation Laboratory

HRA Hot Repair Area

HSS Office of Health Safety and Security

IAS Independent Assessment System

ICAMS INL Corrective Action Management System

INL Idaho National Laboratory

INTEC Idaho Nuclear Technology and Engineering Center

ISM Integrated Safety Management

ISMS Integrated Safety Management System

LLP Lessons Learned Program

LLW low-level waste

LMT Leadership Management Team

LO/TO lockout/tagout

MFC Materials and Fuels Complex

MOP Management Observation Program

MSA management self-assessment

MSL Management System Leads

NEPA National Environmental Policy Act

NFPA National Fire Protection Association

NOV Notice of Violation

NRAD Neutron Radiography Reactor

NSE Nuclear Safety Engineering

NTS Noncompliance Tracking System

OFI opportunity for improvement

ORPS Occurrence Reporting and Processing System

OSHA Occupational Safety and Health Act

PAAA Price Anderson Amendment Act

PDD program description document

PLN plan

PPE personal protective equipment

PNOV Preliminary Notice of Violation

QA quality assurance

QAP Quality Assurance Program

QMS Quality Management System 
RDD\&D research development, demonstration, and deployment

REC Research and Education Campus

RWP radiological work permit

SMC Specific Manufacturing Capability

SME subject-matter expert

SOAR Safety Observations Achieve Results

SPOMC Safety Performance Objectives, Performance Measures and Commitments

SSDRP Safety and Security DOE Regulatory Program

TRCR total recordable case rate

USQ unreviewed safety question

VPP Voluntary Protection Program

ZPPR Zero Power Physics Reactor 
INTENTIONALLY BLANK 


\section{Idaho National Laboratory Integrated Safety Management System 2011 Effectiveness Review and Declaration Report \\ 1. INTRODUCTION}

This document describes fiscal year (FY) 2011 Integrated Safety Management System (ISMS) effectiveness at Idaho National Laboratory (INL) for Battelle Energy Alliance, LLC (BEA). Integrated Safety Management (ISM) for INL is implemented per Department of Energy (DOE) Integrated Safety Management System Policy (DOE P 450.4A), requirements, and guidance in a manner that applies controls and precautions tailored appropriately to the hazards of the projects and work being performed.

\subsection{INL Integrated Safety Management}

ISM at INL comprises:

- The governing policy that safety be integrated into work management and work practices at all levels

- The INL policies, programs, procedures, and culture that fulfill our environmental, safety, health, quality, security, and emergency management responsibilities.

ISM is inherent to our Laboratory's primary mission: to ensure the nation's energy security with safe, competitive, and sustainable energy systems and unique national and homeland security capabilities.

\subsubsection{Guiding Principles and Core Functions of ISM at INL}

Department of Energy Policy 450.4A, Integrated Safety Management System Policy, contains the following seven guiding principles (INL has adopted an eighth guiding principle of "Employee Involvement") and five core functions that provide guidance and requirements to the Department and its contractors for systematically integrating safety into management and work practices at all levels.

The Eight Guiding Principles must be followed in establishing and performing the five core functions to reach the ultimate safety goal of zero accidents, work-related injuries and illnesses, regulatory violations, and reportable environmental releases.

1. Line management responsibility for safety

2. Clear roles and responsibilities

3. Competence commensurate with responsibilities

4. Balanced priorities

5. Identification of safety standards and requirements

6. Hazard controls tailored to work being performed

7. Operations authorization

8. Employee involvement.

Five Core Functions must be applied, on a graded approach, to all work.

1. Define the scope of work

2. Analyze the hazards 
3. Develop and implement hazard controls

4. Perform work within controls

5. Provide feedback and continuous improvement.

Another ISM requirement is that a program description document (PDD) is updated each year and transmitted to DOE for approval. At the INL, PDD-1004 shows how INL implements ISM and incorporates the eight guiding principles of safety and five core functions into work and management at all levels and addresses all types of work and hazards to ensure safety for the workers, public, and environment. PDD-1004 is not an implementing procedure and does not establish requirements; however, it does describe the overall ISM program, high-level key management system interfaces, and how the eight guiding principles of safety and five core functions are integrated with management and work at the Laboratory, facility, and activity levels. Section 1.2 briefly describes the high-level INL ISM implementation.

\subsection{Objective}

An annual ISMS Effectiveness Review is required by DOE ISMS DOE Acquisition Regulation (DEAR) clause 970.5223-1. This assessment will focus on the effectiveness of ISMS implementation in terms of safety performance (including worker safety and health, feedback/improvement, environmental protection, security, emergency management, and quality) and responses to events, assessment results, and lessons learned. The objectives of the annual ISM effectiveness review will

- Determine the effectiveness of the ISMS in integrating safety into work performance, in supporting the safety performance of work, and in improving safety performance

- Identify strengths of ISMS implementation

- Identify weaknesses of ISMS implementation to focus attention on corrective and improvement actions

- Identify opportunities for improvement in efficiency or effectiveness of the ISMS, and identify actions for continuous improvement.

\subsection{Areas of Concern from 2010 Effectiveness Review and Declaration}

FY 2010 annual declaration of the INL's ISMS effectiveness, using one of the three DOE descriptors in DOE M 450.4-1 "Integrated Safety Management System Manual" was "Needs Improvement - ISM is being effectively implemented, but noteworthy weaknesses need to be addressed." Excerpts from the DOE-ID report to headquarters included the following results.

INL made good progress during FY 2010, improving self-critical evaluations of their performance and in identifying areas where they have weakness and need improvement. Once weaknesses are identified, INL develops corrective actions and, generally, completes the corrective actions satisfactorily. However, in 2010, INL's annual ISMS effectiveness review identified noteworthy weaknesses in the areas of work planning and control. Several INL assurance activities including event assessments, corrective action effectiveness reviews, and common cause analyses, along with Department of Energy Idaho Operations Office (DOE-ID) reports including conclusions in a for-cause review, identified that the rate of progress toward implementing corrective actions was not acceptable and that INL needed to accelerate both programmatic and operational improvements. Therefore, INL's level of ISMS effectiveness was deemed in the "Needs Improvement" category. 
This determination was based on performance data, which identified both strengths and weaknesses, as reflected below:

ISM elements have been maintained and improvements have been made. Overall, INL's ISM processes have been functioning adequately. Although the bases for INL programs and processes are sound and most work is completed without issue, when issues do occur, most are related to noncompliance with the process and/or program requirements. INL is working to help sustain highperformance event-free operation, to increase management presence in the field, to improve human performance, to reinforce personal responsibility, and to foster feedback and improvement. Opportunities and ongoing improvement activities include:

- Identified noteworthy weaknesses in the areas of work planning and control and radiological work performance.

- In response to the hazard identification and control process assessment, INL is verifying the effectiveness of individual corrective actions to determine if the actions addressed the issues and recommendations are still being implemented and are effective for minimizing future events.

- Opportunities for improvement are being evaluated that relate to ensuring full understanding of line management, roles and responsibilities, and operations authorization when work space is shared between different organizations and management systems as part of organizations effectiveness.

- In response to the DOE Headquarters' Office of Health, Safety and Security Voluntary Protection Program (VPP) team, INL is currently evaluating the adequacy of controls and documentation when work falls under "routine activity envelope" or is considered "skill of craft."

- In response to improving the Contractor Assurance System (a) actions taken to improve organizational understanding of required assurance implementation activities; (b) better link risk mitigation with assurance; (c) improve the timeliness of identification and documentation of issue, potential weaknesses, or conditions needing management attention and ensuring entry into the Issues Management process from all types of assurance activities; and (d) In general, to improve timeliness of lessons learned reviews and usage of the lesson learned database.

- Weaknesses were identified in FY 2011 for metrics and the use of the INL Corrective Action Management System data in reporting.

- The BEA Operations Committee expressed concern with current safety performance related to situational awareness. They recognized the Safety Leadership Strategy and encouraged management to continue the sustained effort. The goal of the ongoing Safety Leadership strategy is to deepen the commitment to safety leadership, concern for hazards and mitigation controls, shared concern for the impact on people, and continual reflection upon practices through monitoring analysis and feedback systems.

Progress made toward achieving the INL contract's safety objectives and 2010 commitments were satisfied. The 2010 performance measures, which are the indicators that show interim progress toward meeting longer term contract objectives, yielded positive results. INL did have an increase in injury/illness rates in FY 2010. INL tracks leading injuries as one of its annual performance measures which drive the injury/illness rates (total recordable case rate [TRCR] and day away, restricted or transferred [DART]). Historical INL data indicates that sprains, strains, and cut/abrasion injuries comprise the majority of the TRCR and DART cases, and as a result, drive these rates. The TRCR for FY 2010 resulting from strains/sprains and cuts/abrasions was 0.99 , and the corresponding DART Case Rate was 0.56 . These FY 2010 rates represent an increase compared to the FY 2004 baseline TRCR and DART Case Rate values for these types of cases, which were 0.82 and 0.47 , respectively. Introduction of the Safety Leadership Strategy and employee awareness campaigns focusing on injuries resulting from 
slips and falls and having a body part struck by, struck against, or caught in an object have been deployed to specifically address these leading injuries. Results of these efforts are being followed by DOE-ID.

\subsection{Summary of Major Actions and Initiatives to Address Areas of Concern from 2010 Effectiveness Review and Declaration}

\section{Work Planning and Control/Radiological Work/Hazard Identification/Organizational}

Effectiveness. A series of radiological and work control related events occurred during 2010 and early in FY 2011 across the Laboratory that required significant management attention and corrective action. Radiological work at Materials and Fuels Complex (MFC) was suspended in January 2011 and Plan (PLN)-3763, "MFC Recovery Plan" was developed to safely resume work. Additionally, a parallel effort was initiated to address the underlying causes of a number of events, results of INL cause analyses and assessments, and conclusions of DOE reports (including a For-Cause review and Consent Orders). The result of this was the issuance of PLN-3762, "INL Work Control Corrective Action Plan," which initiated improvements in execution of work control, radiological work processes and execution, improvements in Contractor Assurance System processes, and especially underlying factors affecting organizational effectiveness. A new leadership team was established at MFC as part of this initiative, representing the Research Development, Demonstration, and Deployment (RDD\&D) programs, nuclear operations, and facilities organizations to focus on improving communications, organizational relationships, accountability, and operations authorization.

The completion of PLN-3763 at MFC resulted in significant improvements to the level of radiological control and safety. Radiological work procedures were revised to improve consistency and radiological controls were better integrated into work documentation. Work resumed after approximately 3 months and significant effort was made to accomplish as much of the mission work as possible in a safe manner resulting in high-quality products. The lessons learned from this effort were also leveraged LaboratoryWide, through the implementation of PLN-3762. This plan's improvement actions focused on four primary areas: (1) work control and planning, (2) radiological work, (3) organizational effectiveness, and (4) contractor assurance.

In addition to the focused radiological control improvements at MFC, a Radiological Control Road to Excellence Plan was developed that addresses all peer/external review recommendations and lessons learned into a comprehensive plan intended to bring the Radiological Control Program to excellence. Results from this initiative will be shared with DOE-ID routinely and resources will be dedicated to address improvements and issues as necessary.

Several independent assessments by INL and DOE have validated that these plans have resulted in improved performance, in particular the positive effects of Laboratory-Wide implementation of a formal documented Management Observation Program (MOP). The centerpiece of the plan's actions to improve organizational effectiveness is increased management presence and engagement in the field, which has led to reinforcement of standards for performance and in several cases, has resulted in identifying and correcting precursors to events. INL conducted two interim effectiveness reviews for PLN-3762 and PLN-3763 in July 2011. The latter assessment determined that PLN-3763 was effective in achieving its aim of allowing safe resumption of radiological work at MFC. The assessment of PLN-3762 was designed as an interim or midcourse check to determine whether actions had begun having the intended effect and were showing indications of sustainability. This assessment concluded that the actions of the plan were implemented, had resulted in improvement, and that continued effort to make them sustainable should produce the intended results. DOE performed an assessment in August and September of the effectiveness of PLN-3762 and concluded that the plan to date was marginally effective - the actions of the plan had been implemented and resulted in improvement in work control, radiological control program and execution, organizational effectiveness, and Contractor Assurance effectiveness with 
additional effort needed to produce sustainability and improve the consistency of application of INL work processes. DOE-HSS also performed an assessment as part of an assist visit of the INL Radiological Protection Program in June and concluded that the program was adequately implemented.

These assessments and event data indicate that the actions from PLN-3762 and PLN-3763 have produced positive results, but have not completely eliminated incidents; for example, there have been events such as the recent radiation exposure incident at Materials and Fuels Complex (MFC), the recent burn from an unfocused laser beam at Specific Manufacturing Capability (SMC), the low level drain down at the Advanced Test Reactor (ATR), and inadequate pre-operational cooling supply valve line up checks at the Neutron Radiography Reactor (NRAD). In addition to continuing efforts to complete the actions of PLN-3762, which are focused primarily on maturing and sustaining the initial actions, INL management has kicked off a "sustained operational improvement" initiative to leverage the success of these plans and drive continual improvement, with the ultimate goal of establishing lasting operational excellence at the Laboratory. This long-term initiative began early in FY 2012 and has aggressive goals for significant sustained improvement.

A new leadership team has been created at MFC to help better understand the mission and how each individual contributes to the success of INL. Facility availability for research is a priority and is being improved through better planning and prioritization of maintenance activities. Continual organizational and process improvements are occurring through the MFC leadership by the Barrier Removal Team and plan of the day meetings. Overall, communications have significantly improved and teamwork is a central theme relating to the accomplishment of the mission. There is a newfound bias for action, emphasizing accountability and ownership that is leading to improved performance.

Adequacy of Controls for "Skill of the Craft." During the first triennial VPP recertification in 2009, the Office of Health, Safety and Security (HSS) DOE-VPP Team performed a review from October 19 to 30, 2009, in which they concluded that no hazard analysis is documented if the determination in the scope of work falls under "routine activity envelope" or "skill of craft". The hazards and risks are considered low and the performer is considered to have sufficient training and knowledge to perform the work safely. The HSS team noted several examples where additional controls from a documented hazards analysis might have improved the performance and execution of low hazard high frequency work activities. The HSS team recognized the reliance INL places on worker skill and awareness for routine, low-risk work and suggested that INL should revise its work control processes to ensure hazard analysis is documented for all work and that definition as routine activity or skill of the performer is based on the documented hazard analysis.

This suggestion was also pointed out in the FY 2010 ISMS Effectiveness Review. The following actions have taken place or are in progress as a result of the 2010 ISMS Effectiveness Review:

- LWP-21220, "Works Management," was revised as stated in the ICAMs response to relocate decision step for the determination of Routine Activity Envelope applicability until after initial hazards analysis has been completed. The revision of LWP-21220 also converted the procedure from an electronically delivered process to a flat file and is in the final stages of review.

- An evaluation was performed on the use of the OSHA 3071, 2002 (revised) to analyze routine hazards. LWP-21220, was designed to align with and execute the 5 core function of Integrated Safety Management System. As such, LWP-21220 is consistent with the OSHA Job Hazard Analysis (JHA) process for analyzing 'routine' hazards.

- Several organizations have developed Laboratory Instructions to cover routine hazards (e.g., F\&SS Machine Shop, Transportation Maintenance Shop "Big Shop," and Nuclear Maintenance). Additional Laboratory Instructions addressing routine hazards will be developed as the need is identified. INL launched a Sustained Operational Improvement Initiative in late FY 2011 which includes actions to 
enhance LWP-6200, "Maintenance Integrated Work Control Process." These enhancements include revisions to the planning level screening criteria (tool pouch, minor maintenance, planned work) to provide better consistency in the screening process, attendant review of the "Skill of the Craft" checklists to ensure that CCR can be demonstrated for routine hazard mitigation, and development of laboratory instruction for routine hazards that are not addressed by skill of the craft. Additional training will be provided to individuals that perform work screening activities using a blended delivery method (dynamic learning activities) to ensure routine hazards are appropriately addressed.

Previous internal and external assessments, including this annual ISMS review identified that work planning and lack of documented hazards analysis associated with skill of craft and routine activity envelope has not been sufficient to ensure safe and successful operations. Corrective actions have been formulated to address the perceived shortcomings but have not been completely effective as evidenced by continued events associated with work planning and execution for skill of the craft and routine activity envelope activities.

When hazards are not identified, analyzed, mitigated, and communicated to the worker, the worker becomes the last line of defense. Documented evidence that this dialogue has taken place for skill of the craft and routine activities establishes defined boundaries and alleviates unnecessary vulnerabilities to the INL.

Contractor Assurance System (CAS) Implementation/Metrics. In FY 2011, the INL CAS has seen improvements in the use and ownership of the system and tools. This is especially evident in improvements in the planning and execution of risk-informed assurance activities, the increased use of high-volume/low threshold issues management system and INL leadership and engagement in ensuring the effectiveness of corrective actions. Notable examples included the successful rollout of a management observation program (discussed previously), broader establishment of CARBs - driven by PLN-3762, and the formation of a cross-organizational project team to institute more global improvements to the issues management program.

This has resulted in INL witnessing a dramatic increase in documented evidence of leadership engagement with staff in the field. Significant effort has been put into collectively designing programs in a way that will provide INL-wide trending data related to the work control process execution and better enable targeted corrective actions and process improvements. Quarterly reporting of management observations and other assurance activity to the INL governance councils has resulted in broader and increased engagement in understanding the health of the INL and is driving improvements in performance measuring.

The CAS elements of cause analysis, event investigations, and critiques have improved with respect to their quality, rigor and effective mentorship. This was recently seen in the depth and breadth of the recent Low Level ATR Reactor Vessel investigation, causal analysis, and Corrective Action Plan (CAP). The increasing visibility and attention to the corrective action process by management has been noteworthy and will be continuously reinforced in FY 2012.

Performance review meetings held with all directorates in FY 2011 included discussions of CAS expectations. Topics included the importance of linking risk mitigation to specific assurance activities, understanding required assurance activity expectations, ensuring appropriate entry of issues into the Issues Management Tracking System, improving the timeliness of lessons learned reviews and usage of the lessons learned database, and the reporting of performance analysis through the quarterly assurance reports. 
Additional FY 2011 CAS accomplishments included:

- Quarterly Portfolio Status reports providing current status, performance, and emerging risks reported to Governance Councils

- Contractor Assurance Dashboards are more widely used by governance councils

- Assessments continue to improve in quality and focus on performance

- Integrated Assessment System database upgrades (link to ICAMS and Electronic Documents Management System [EDMS] records, requires risk-rank field)

- MOP implementation (all managers, all organizations)

- Cross organizational team efforts for issues management

- Trending, discipline code usage, training, reporting, process integration

- Implementation of Research and Education Campus (REC) and Central Facilities Area (CFA) CARBs

- Multidiscipline participation in CARBs across the Laboratory

- Revision of INL critique process to include Extent of Conditions and lessons learned

- Improvement in quality of formal causal analyses

- Trending and analysis guide developed

- ICAMS classroom training developed

- Piloted training for CAP development.

The INL CAS continues to face a challenge of promoting the right balance of assurance activity that enables INL to find, understand, and correct deficiencies; and improve performance while ensuring organizations are not burdened with nonvalue-added activity. The principle of reasonable assurance recognizes that management controls must be both effective and efficient and applied in a manner commensurate with the risks, mission, and activities of the implementing organizations. It recognizes that the potential for deficiencies, errors, or events remains, but that upon discovery, management action will be undertaken promptly to address shortfalls, omissions, or errors in order to minimize the impact of such events and to learn from those events so as to drive improvement. Sustainment of CAS improvement actions, such as increased management engagement in the field, is critical to the effective execution of long-term solutions to CAPs.

Issues Management and Tracking System. The ICAMS is the INL-standard comprehensive tool for problem reporting, tracking, and resolution. ICAMS

- Serves primarily as a key tool for continuous improvement of INL processes, procedures, and work execution in keeping with guiding principles of ISMS

- Provides a graded approach to resolving problems identified through assessments, occurrences, or by management and employee observations

- Is a powerful management tool, which provides:

- A way to capture high volume, low threshold observation data

- Tracking and trending analysis so managers can identify and correct smaller issues before they can turn into larger problems

- A way to ensure that the issues needing attention reaches the right management and/or organizations at INL. 
Risk-informed assurance activities are planned, executed, and closed out in a timely fashion; are identifying substantive issues; and are followed by appropriate and timely corrective actions. Assurance tools are strategically utilized to assess and monitor any identified or potential areas of risk. Notably are the timely use of targeted management observations to validate behavior changes associated with corrective actions, and the initiation of in-process effectiveness reviews to provide feedback and facilitate any corrective action course corrections or enhancements. Management has documented increased oversight and review of assurance products in Management Review Committees and CARBs. The sitewide self-identification of issues ratio more than doubled in FY 2011. The percentage of scheduled assessments completed reached $90 \%$ (above the goal of $80 \%$ ), with an average of $86 \%$ of the activities associated with an identified risk.

The effectiveness of safety management programs, including those credited in the safety bases for nuclear facilities, are adequately assessed. Each FY 2011 quarterly report included examples of satisfactory compliance and effectiveness for safety management systems. These data are captured in the Integrated Assessment System database and the ICAMS. Safety Management Program assessments have provided substantial issues and actions leading to overall continuous performance improvement and enhanced safety.

Continuous improvement in the implementation of a high volume, low threshold issues management system is evident in accordance with an implementation plan adopted by the pilot working group. Use of high volume, low threshold issues management has steadily matured through FY 2011, with annual usage commensurate with nuclear industry metrics obtained from the Corrective Action Program Owner's Group. The initiation of a structured MOP has greatly contributed to the relevance of the data being collected in the ICAMS. Fundamental elements of cognitive trending are being demonstrated and acted upon at facilities with high activity levels. Where activity is lower, self critical observations with associated individual corrective actions are in evidence and documented in ICAMS.

Improvement is still needed in entering issues into the ICAMS for tracking, management and resolution and timely completion of ICAMS causal analysis and planning phases. An Issues Management Improvement Implementation Plan to provide continuous improvement in the implementation of a high volume, low threshold issues management system was developed in FY 2011 and focused on the areas of training, trending, discipline code structure, and integration. These primary areas were determined through an external assessment (IAS 101959).

An assessment based on recommendations from IAS 101959 is being conducted to close-out FY 2011 issues management improvement actions and evaluate the state of Issues Management with respect to the original improvement plan gap areas.

Operational events are adequately critiqued, reported, and investigated, with appropriate and timely corrective actions. Appropriate analysis and trending is performed and lessons learned are applied sitewide. The quality of event investigation and organizational learning was a strong focus of INL leadership and INL Governance Councils. Additional CARBs have been established through formal charters and have provided oversight of contractor assurance products; including corrective actions, action plans, assessment results, extent of conditions, and event analysis resulting in continuous quality improvement. Leadership demonstrated active management of CAPs by providing priority guidance and adequate resources. Extent of condition assessments has provided valuable insight for the practical application of lessons learned sitewide. Strategic use of in-process effectiveness assessments and trending of targeted management observations have validated corrective action effectiveness, corrective action sustainability, and provided indication of desired behavior changes.

All assessment results, performance metrics, plans, schedules, issues management data, and other CAS products are readily available for review and analysis to DOE-ID. Any issues or requests for data 
were resolved in a timely manner through communications with system experts, email, and one-on-one meetings with product owners.

Achieving a Safety Breakthrough through Safety Leadership. Improving our injury and illness rates continues to present challenges requiring aggressive actions on multiple fronts to impact the bottom line. INL is making progress, and there are successes to celebrate. Of the 19 major organizations within the laboratory, 10 completed FY 2011 without incurring an Occupational Safety and Health Act (OSHA) recordable injury or illness, and 13 completed FY 2011 without incurring a DART case. Additionally, in early July, employees at the entire ATR Complex completed 1 full year without incurring an OSHA recordable injury or illness. The resulting INL FY 2011 OSHA recordable case rate of 0.96 represents an improvement of almost 30\% compared to the FY 2010 rate of 1.37 , and is over $19 \%$ better than the FY 2004 baseline rate of 1.19. The FY 2011 INL DART case rate of 0.50 represents an improvement of over 32\% compared to the FY 2010 rate of 0.74 , and is $18 \%$ better than the FY 2004 baseline rate of 0.61. This year's injury/illness rates represent one of INL's best years. We must break past this point for continued progress. The causes of injury and illness, the challenges they create, and the fact that unique mitigations are the key to preventing injury and illness are understood. A focus on heightened staff attention and awareness, and a Fitness for Duty initiative designed to ensure employees are physically capable and ready to perform their job tasks are improving INL's performance. An increased emphasis on communicating with employees and taking actions to reinvigorate the management observation process are producing results. Managers have been challenged to increase their presence at worksites and increase safety-related interactions with employees.

\subsection{FY 2011 Corrective Action Review Summary}

Analysis of the "Core Functions" and "Guiding Principles" corrective actions, indicate that our largest opportunity for improvement is in the preparation activities (i.e., defining the work, identifying the hazards) prior to releasing and performing the work. It should be noted that during the review it was noticed that several examples of the failures in defining the work were a result of scope creep. (See Appendix A section A-2 for more detail)

Even though corrective actions are generally lagging indicators, in this case, the activities and attention devoted to fixing the areas of defining, planning, and mitigating the work demonstrates they are good leading indicators signifying effort that should be emphasized during the processes prior to work being performed. Ensuring that training, responsibilities, and expectations are explained and understood, a well defined scope is in place, and that issues associated with the work to be performed have been addressed and resolved prior to work being performed are critical for the success of completing work safely.

At the beginning of FY 2012, INL experienced an airborne event that potentially exposed 16 workers. The cause analysis and accident investigation will likely indentify further improvement opportunities for ISMS. It also serves as an indicator that ISMS needs improvement.

\section{ISMS SAFETY PERFORMANCE OBJECTIVES, PERFORMANCE MEASURES AND COMMITMENTS}

INL annually develops a set of performance measures for each fiscal year that establish specific key performance and improvement initiatives. INL was effective in meeting most of the submitted and approved SPOMC for FY 2011. Many improvements have resulted from the implementation of PLN-3762 and other initiatives are on track for making additional improvements. INL is committed to dedicating resources to ensure that the desired outcomes are achieved, which is evidence of having a strong core value of a successful ISM program. It will take time for the changes and improvements to 
become effective in achieving the desired expectations and therefore the rating of "Effective with Needs Improvement" will remain the current status of INL's ISM program.

\subsection{Status and Summary of FY 2011 Measures}

FY 2011 SPOMC metrics were submitted and approved as follows:

- Quality of Assessment

- Proactively self-identified versus self-revealed

- Recurring Issues

- NOVs

- Reportable Releases

- Waste Diversion

- Nuclear Safety Severity Index

- Electrical Severity Index

- Leading Injuries Which Drive the BEA TRCR and DART

- Unprotected Exposures Exceeding Threshold Limit Values or Permissible Exposure Limits

- Contamination/ Radiation Control Events

- Reportable Personnel Radiation Exposures

- Reportable Events Attributable to a Less-Than-Adequate Work Management Process

- Work Management Related Issues and Concerns

\section{Quality of Assessment - Marginally Effective}

Assessment Evaluation Board (AEB) completed the third quarter reviews using the new criteria and piloted it with three assessments. The new criterion raises the level of performance expectations focusing on valued outputs from the activity and minimizing process evaluation. The average score for the quarter was $74 \%$, which is an expected drop.

A revised process will be implemented in FY 2012 to conduct monthly AEB reviews; however, the number will be reduced and will focus primarily on Operations, Science and Technology, and Management System owner activities.

The AEB has been chartered to conduct focused evaluations of management and independent assessments to determine their effectiveness as part of the Price Anderson Amendment Act and DOE HSS CAPs. The products of the AEB include: (a) Individualized feedback to organizations and personnel conducting assessments, and (b) consensus report to the INL Councils identifying the Laboratory's performance related to the conduct of assessments.

Analysis of the weaknesses in lower scoring assessments from this quarter's AEB indicates that assessment reports are likely to be more thorough and better planned then the reports indicate.

Assessment reports are not providing enough objective evidence and information in the reports for the readers to come to the same conclusion as the assessment team.

Proactively self-identified versus self-revealed - Effective but Needs Improvement 
Overall Score is "Effective but Needs Improvement." Improvement is needed to ensure leading indicators are identified and utilized to prevent operational events. Metrics indicate for FY 2011 a high percent of proactively identified issues. The proportion of issues that were proactively identified (through planned assessments, performance reviews, surveys, peer reviews and metric trend analyses, and unplanned employee observations) improved to $97 \%$, well above the target of $90 \%$ (see Table 1) during the fourth quarter of FY 2011. The number of issues/observations being entered into the system has significantly increased with the implementation of the high volume, low consequence Issues Management System. It should also be noted that positive observations and noteworthy practices are also being reported; 203 in the fourth quarter. These data indicate the INL is effective at proactively identifying issues. Continued improvement is needed to self-identify conditions and behaviors that could lead to significant issues or events.

Table 1. Proactively identified issues.

\begin{tabular}{|c|c|c|c|c|c|c|c|}
\hline Metric & Target & $\begin{array}{c}\text { FY } \\
2009\end{array}$ & $\begin{array}{r}\text { FY } \\
2010\end{array}$ & $\begin{array}{c}\text { FY } 2011 \\
1 Q\end{array}$ & $\begin{array}{c}\text { FY } 2011 \\
2 Q\end{array}$ & $\begin{array}{c}\text { FY } 2011 \\
3 Q\end{array}$ & $\begin{array}{c}\text { FY } 2011 \\
4 Q\end{array}$ \\
\hline \multirow{3}{*}{$\begin{array}{l}\text { Origin of } \\
\text { Issues } \\
\text { (\% proactively } \\
\text { Identified) }\end{array}$} & $>90 \%$ & \multirow{3}{*}{$92 \%$} & & \multirow{3}{*}{$92 \%$} & \multirow{3}{*}{$96 \%$} & \multirow{3}{*}{$96 \%$} & \multirow{3}{*}{$97 \%$} \\
\hline & $80-90 \%$ & & $94 \%$ & & & & \\
\hline & $<80 \%$ & & & & & & \\
\hline
\end{tabular}

Eighty-nine conditions revealed themselves to BEA in the fourth quarter of FY 2011.

BEA is monitoring the level of low threshold, high volume numbers being entered into ICAMS and other systems based on organizational function and/or activity (Table 2). The data indicate that with one exception, improvement has occurred on the entry of low threshold, high volume issues. One significant issue was identified by BEA management observation. The condition indicated that a Work package did not address entry into Confined Space Permit Required space. No DOE findings resulted in significant conditions.

Table 2. Origin of issues by organization function and/or activity.

\begin{tabular}{|l|c|c|c|c|c|c|}
\hline \multicolumn{1}{|c|}{ Function/Activity } & April & May & June & July & August & September \\
\hline Science and Technology & 27 & 157 & 118 & 131 & 152 & 86 \\
\hline Nuclear Operations & 481 & 499 & 535 & 387 & 643 & 537 \\
\hline Facilities and Site Services & 141 & 75 & 129 & 91 & 122 & 66 \\
\hline Laboratory Protection & 31 & 37 & 72 & 65 & 85 & 52 \\
\hline ES\&H Program & 43 & 37 & 24 & 68 & 40 & 61 \\
\hline Support Programs & 87 & 97 & 114 & 76 & 70 & 62 \\
\hline
\end{tabular}

\section{Recurring Significant Issues - Effective but Needs Improvement}

No recurring significant issues were reported in ICAMS during the fourth quarter of FY 2011. However, CAS recognizes there is improvement needed related to work control and radiological control issues. Working groups and initiatives have been established to address these areas. CAS will continue to monitor progress over FY 2012. 


\section{Notices of Violation - Effective}

Seven inspections were conducted by external regulators during FY 2011 resulting in no notices of violation. The regulators elected to issue warning letters rather than notices of violation in two of the inspections because of timely disclosure and effective preventive actions by BEA. The EMS is viewed as effective in this area because the issues were managed in a manner that prevented the issuance of notices of violation.

\section{Reportable Environmental Releases - Effective}

No reportable environmental releases occurred during FY 2011. The EMS is viewed as effective in this area because releases that did occur in FY 2011 were appropriately managed and did not become reportable.

\section{Waste Diversion - Effective}

Waste diversion in FY 2011 continued to expand to include in-town and Site facilities. Diverted from landfills during the year were 745,000 lb of office materials. The amount of material diverted increased from 28,000 lb in July to 73,000 lb in September, showing steady improvement. Because of the ongoing expansion of the waste diversion program, the EMS is viewed as effective in this area.

\section{Nuclear Safety Severity Index - Effective}

The Nuclear Safety Severity Index was adopted by INL from DOE-ID, including the criteria, score ranges, and the annual performance goal of $\leq 125$ was met.

\section{Electrical Severity Index (ESI) - Effective}

Monitoring of electrical safety performance has been established as a mechanism to evaluate historical data relative to electrical events to identify potential trends, repetitive events or single point failures that may indicate an opportunity for improvement of the electrical safety program and related processes. The INL has used the EFCOG Electrical Severity Measurement Tool since FY 2006 to evaluate events and calculate the Electrical Severity Index (ESI). The ESI is calculated when each event is weighted for severity, averaged with other events, normalized against man hours and graphed to create the ESI. Overall, the INL trend in electrical safety event severity and frequency has been favorable and the performance goal of $=151$ was again achieved. The ESI 12 month rolling average was 22 for the year and no occurrences resulted in electrical injury or unsatisfactory performance. This performance provides an indication that the interventions and actions implemented in response to past events has been effective.

\section{Leading Injuries - Effective but Needs Improvement}

Historical data indicate that sprain/strain injuries and cut/abrasion injuries comprise the majority of the TRCR and DART cases. Reducing the occurrence of these specific types of occupational injuries should reflect positively in reducing BEA's overall TRCR and DART Case Rates. During FY 2011, 32 of the 38 cases meeting the criteria for classification as OSHA Recordable involving BEA employees were comprised of either a sprain/strain or a cut/abrasion injury. As a result the TRCR for FY 2011 resulting from strains/sprains and cuts/abrasions is 0.80 , and the corresponding DART Case Rate is 0.40 . This represents a decrease compared to the 1.04 TRCR for FY 2010 for the same types of injuries, as well as the corresponding 0.63 DART Case Rate. Comparison to the FY 2004 baseline TRCR (0.82) and DART Case Rate (0.47) values for these types of cases is also favorable. However, additional improvements are necessary to reach BEA's overall goal to have a 50\% improvement in the total recordable and DART Case rates, as compared to the baseline, by the end of FY 2014. As a result, the current status of the effectiveness of BEA's efforts in this regard is "Effective, but needs improvement." 


\section{Unprotected Exposures Exceeding Threshold Limit Values or Permissible Exposure Limits- Effective}

No unprotected overexposures exceeding established Occupational Exposure Limits occurred during FY 2011.

\section{Contamination / Radiation Control Events - Effective but Needs Improvement}

Contamination / Radiation Control Events reported in ORPS as Reporting Group 6, Contamination/Radiation Control, Subgroups A, B, and D. (Exception: Group 6, Subgroup B, Spread of Radioactive Contamination, Sequence (4) which strictly addresses legacy radioactive contamination resulting from historical operations that are unrelated to current activities.) Objective: No reportable contamination/radiation control events. During FY 2011, six radiological events were reported in ORPS this year. This is short of the goal of zero, but is still considered effective but needs improvement.

\section{Reportable Personnel Radiation Exposures - Effective}

Personnel Exposures greater than planned reported in ORPS as Reporting Group 6, Contamination/Radiation Control, Subgroup C, Radiation Exposures, Sequence (3). Objective: No reportable personnel radiation exposures. During FY 2011, no reportable radiation exposures occurred. This meets the goal and is considered effective.

\section{Reportable Events Attributable to a Less-Than-Adequate Work Management Process - Effective but Needs Improvement}

The goal of less than $5 \%$ was not achieved but rather $21 \%$ of the reportable events were attributable to less-than-adequate implementation of one or more elements of the approved BEA work control process, such as inadequate management and supervisory methods, less than adequate Human Performance, and failure to follow an approved, documented work control or hazard mitigation procedure/process.

\section{Work Management Related Issues and Concerns - Effective Needs Improvement}

See section 1.4 and Appendix A for extensive discussion.

\subsection{Status and Summary of FY 2011 Safety Performance Commitments}

Federal Electronics Challenge Silver Status - Effective

DOE-ID and the INL received a bronze Federal Electronics Challenge award for their FY 2010 activities. The award was presented at a ceremony in Washington, D.C., in September 2011. FY 2011 activities are completed for the 2012 Federal Electronics Challenge silver award application.

\section{Obtain Voluntary Protection Program Recertification - Effective}

INL- BEA VPP Safety Successes - BEA VPP at the INL achieved many successes over the past year on the path toward STAR recertification anticipated to be conducted in 2012. A few noteworthy accomplishments in Community Outreach and Employee Involvement are mentioned below.

Community Outreach - At INL, innovation is a key factor in developing solutions to energy problems. Innovation in how we approach research and review our processes, and now, after INL's VPP 
was honored with the 2011 VPPPA Region X Innovation Award and one of two distributed National VPPPA Safety and Health Outreach awards, it is clear that the Laboratory uses innovation in our safety programs.

VPP volunteers continue to share INL's safety messages to communities. In May, VPP sponsored two Farm Safety Day events in the Idaho communities of New Plymouth and Roberts. In August, VPP focused efforts to reduce distracted driving by distributing "Don't text and Drive" thumb rings at Community Night Out in Idaho Falls.

Employee Involvement - The INL experienced organizational changes that resulted in the need to reorganize the EST at the Research and Education Campus. The new structure is a hybrid of dividing between organization and building. As a result of the reorganization, VPP continues to expand the number of individuals that serve in leadership positions on ESTs.

The Laboratory EST and the VPP office sponsored Safety Recognition Week in June 2011. The theme was "Safety in All Places." All ESTs sponsored daily activities to assist employees to focus on Safety 24/7. The first week in November, ESTs distributed ice scrapers and flashlights to assist in preparing employees to be safe during the winter season as well as during the daylight savings time change.

ES\&H recognized BEA employees for reaching a milestone along the journey to safety excellence in November 2011. ESTs distributed Camelbak hydration bottles to all BEA employees. FY 2011 ended with a total recordable case rate of 0.96 , an improvement of almost $30 \%$ compared to FY 2010s rate of 1.37. The resulting DART case rate for FY 2011 ended at 0.50 , an improvement of over $32 \%$ compared to FY 2010s rate of 0.74 .

Maintain a high-volume, low-threshold issues management system - Effective

See section 1.4 and Appendix A for extensive discussion.

\subsection{FY 2012 Safety Performance Objectives and Commitments}

- Federal Electronics Challenge Silver Status

- Obtain Voluntary Protection Program Recertification

- Maintain a high-volume, low-threshold issues management system.

\subsection{FY 2012 Safety Performance Measures}

The continual improvement and maturation of INL contractor assurance processes, particularly with respect to the Management Systems that had responsibility for reporting progress on the approved SPOMC measures, has led to an agreement between DOE-ID and INL that will utilize the metrics that INL currently reports on in the Quarterly Performance Portfolio Reports as the established measures for FY 2012. These measures within the quarterly reports provide a more comprehensive and in-depth look at the management systems and several different useful data points that enable the management system leaders to maintain a pulse on effectiveness and areas for concern of their respective organizations. Embodied in those measures are also the previous specific SPOMC. DOE has agreed that the measures within these quarterly reports will satisfy the SPOMC requirement. The management system leaders will still maintain the flexibility to adjust their monitoring of these measures based on risks and priorities within their management systems. INL has also agreed to keep DOE informed of any major changes to the report structure and measures that are currently reported on and work closely with their DOE 
counterparts on any future potential measures. Future evaluation of ISMS SPOMC commitments will be based on this working relationship and effective measurement of applicable areas.

The FY 2011 review and revision of PDD-1004 "Integrated Safety Management," will reflect the changes to this process and provide clear guidance for Management System Leaders on the associated expectations and fulfillment of requirements that their quarterly reports satisfy for FY 2012.

\section{EFFECTIVENESS REVIEW RESULTS}

The effectiveness review resulted in no additional issues that weren't already identified and addressed as described in this report, six Observations, and two Recommendations.

\section{A. Issues}

No additional issues that are not already being addressed.

\section{B. Observations and Opportunities For Improvement}

1. INL has dedicated a significant amount of resources devoted to performance assurance. The performance assurance activity results that were reviewed indicate that the majority of the corrective actions are focused on improving the activities associated with defining the work and identifying the hazards. The "after the fact efforts" would be more effective up front in the planning process to prevent unexpected consequences.

2. INL needs to continue with the efforts associated with PLN-3762, follow up with the appropriate effectiveness reviews, and make adjustments as necessary to sustain improvement.

3. Work performed under skill of the craft and routine activity envelope remains one of the biggest challenges for INL. Several internal and external assessments have identified concerns, that the lack of documented hazard analysis associated with these type activities is ineffective. There are numerous examples of undesired outcomes that have resulted from INL taking too much credit for hazards control by utilizing skill of the craft and routine activity envelope. When an evolution of activities are performed concurrently additional hazards become evident and reliance of skill of the craft and routine activity envelope preclude appropriate planning of the work and hazard mitigation processes. The opportunity to refresh awareness with individual workers of hazards associated with routine activities is also lost.

4. There was limited information on assurance activities associated with guiding principles 2 and 7. Assessments rarely targeted operations authorization processes for improvement. Performing assessments focused on operations authorization and clear roles and responsibilities will emphasize attention to ensure a well defined scope, personnel are qualified, briefed appropriately, and authorized to perform assigned tasks.

5. The TRCR for FY 2011 resulting from strains/sprains and cuts/abrasions is 0.80 , and the corresponding DART Case Rate is 0.40 . This represents a decrease compared to the 1.04 TRCR for FY 2010 for the same types of injuries, as well as the corresponding 0.63 DART Case Rate. Comparison to the FY 2004 baseline TRCR (0.82) and DART Case Rate (0.47) values for these types of cases is also favorable. However, additional improvements are necessary to reach BEA's overall goal to have 
a 50\% improvement in the Total Recordable and DART case rates, as compared to the baseline, by the end of FY 2014. As a result, the current status of the effectiveness of BEA's efforts in this regard is "Effective, but needs improvement."

6. The INL CAS has seen improvements and maturation in the use and ownership of the system and tools resulting in improvements in the planning and execution of riskinformed assurance activities. The increased use of high-volume, low threshold issues management system and INL leadership and engagement is ensuring the effectiveness of corrective actions. The steps taken to maintain the management systems and assurance portfolios in alignment with the strategic direction of the INL have contributed to the effectiveness of the CAS to provide accurate and valuable feedback to senior INL Management.

\section{A. Recommendations}

1. INL should continue to improve and implement a more robust work management process that dedicates focused resources and efforts to the implementation of the first two core functions, define work and analyze hazards. This expanded effort prior to releasing the work activities will result in fewer incidents and less follow up corrective actions. This process should include:

- Documented hazard analysis for most work activities of moderate hazard work and above, and less reliance on work authorized under skill of the craft and routine activity envelope

- A process that requires a well-defined and documented work scope that does not allow for deviation from the work activity as defined (scope creep)

- Continued improvement in documented briefing requirements and implementation

2. INL should perform focused reviews that include operations authorization and clear roles and responsibilities in performance assurance activity schedules for FY 2012.

3. Continue efforts in the "Sustained Operations Initiative" and "Road to Excellence Radiological Control Plan".

\section{B. Noteworthy Practices}

The level of attention and resources that INL dedicates to the improvement of processes and resolutions of issues is appropriate and evidence of an effective ISMS program. The target is not always hit initially, but INL never loses sight of the target.

\section{Conclusion}

The information presented in this review shows that INL has a well-defined and effective ISM program with effective performance; however, the need to stay the course and continue to improve work planning and control initiatives that are being implemented should remain the priority in order to not repeat similar occurrences and reduce events in the future. It will take some time to fully implement the improvements that have been made and to engrain new behaviors that will achieve the desired "Effective Performance." 
INL implemented an effective ISM program with built-in feedback and improvement mechanisms during FY 2011. INL performance actively sustains efforts to ensure effective ISM implementation and a positive culture that supports environmentally safe and highly productive operations. Considerable progress has been made toward ensuring the safety of our workers and environment. It is recognized that continuous improvement is always the goal and expectation.

The evaluation of ISM, based on performance data between October 1, 2010, and September 30, 2011, identified strengths and areas for continuous improvement and led to the following overall conclusions about the status and effectiveness of the INL ISM.

All ISM elements have been maintained and many have been improved. The ISM processes have been functioning properly. No elements of the system were identified as having degraded and numerous improvements have been implemented. Scheduled ISMS refresher training for all employees and a more in-depth course for line managers will commence in January 2012.

The system is effective for performing work safely. The INL ISMS continues to be a well-designed program focused on continuous improvement that ensures work is accomplished in a manner that protects workers, the public, and environment. For FY 2010 INL declared that ISM was being effectively implemented, but that noteworthy weaknesses in work planning and control needed to be addressed. In FY 2011, key corrective actions and initiatives underway to correct these weaknesses are having the intended effect. Although individual events indicate isolated problems with processes and implementation, the system as a whole is sound and ensures safe performance of work when implemented as demonstrated by work accomplishments in FY 2011. Program effectiveness is also substantiated by a number of indicators, performance analyses, data trending, work accomplishments, and assessment results.

Opportunities for improvement have been identified. INL feedback and improvement processes identified weaknesses in work planning, work control, and in-field supervision. Expectations for adhering to risk and procedure requirements were not being consistently reinforced by line management, which sometimes caused risk to be managed at too low a level with organizations. Corrective actions for this were incorporated into a comprehensive sitewide PLN-3762 and are in progress. These assessments and event data indicate that the actions from PLN-3762 and previous action plans such as PLN-3763 have produced positive results, but have not completely eliminated incidents; for example, there have been events such as the recent the radiation exposure incident at Materials and Fuels Complex (MFC), the burn from an unfocused laser beam at Specific Manufacturing Capability (SMC) and inadequate pre-operational cooling supply valve line up checks at the Neutron Radiography Reactor (NRAD). In addition to continuing efforts to complete the actions of PLN-3762, which are focused primarily on maturing and sustaining the initial actions, INL management has kicked off a "Sustained Operational Improvement Initiative" to leverage the success of these plans and drive continual improvement, with the ultimate goal of establishing lasting operational excellence at the Laboratory. This long-term initiative began early in FY 2012 and has aggressive goals for significant sustained improvement.

Opportunities to improve INL training programs and strengthen the ISMS principle of Competence Commensurate with Responsibility were also identified early in FY 2011 and actions have been taken to take advantage of these opportunities. 
Battelle Energy Alliance, LLC, strongly supports ISMS functions and principles and is committed to continual improvement. All work at INL is managed by processes and procedures that implement the ISMS five core functions and eight guiding principles. INL leaders and workers demonstrate a strong, genuine, continual, and personal commitment to ISMS elements at the laboratory, facility, and activity level. The purpose of this review is to evaluate the major "evidence" from assessments, focus on specific issues, and evaluate overall performance while providing a summary of strengths, weaknesses, ongoing improvement initiatives, and additional opportunities for improvement as they relate to ISMS.

\section{Overall Performance Rating - Needs Improvement}


Appendix A

\section{Supplemental Analysis and Discussion}




\section{Appendix A}

\section{Supplemental Analysis and Discussion}

\section{A-1 SUMMARY OF MAJOR ACTIONS AND INITIATIVES TO ADDRESS AREAS OF CONCERN FROM 2010 EFFECTIVENESS REVIEW AND DECLARATION}

Work Planning and Control. A series of radiological and work control related events occurred during 2010 and early in FY 2011 across the Laboratory that required significant management attention and corrective action. Radiological work at Materials and Fuels Complex (MFC) was suspended in January 2011 and Plan (PLN)-3763, "MFC Recovery Plan" was developed to safely resume work. Additionally, a parallel effort was initiated to address the underlying causes of a number of events, results of INL cause analyses and assessments, and conclusions of DOE reports (including a For-Cause review and Consent Orders). The result of this was the issuance of PLN-3762, "INL Work Control Corrective Action Plan," which initiated improvements in execution of work control, radiological work processes and execution, improvements in Contractor Assurance System processes, and especially underlying factors affecting organizational effectiveness. A new leadership team was established at MFC as part of this initiative, representing the Research Development, Demonstration, and Deployment (RDD\&D) programs, nuclear operations, and facilities organizations to focus on improving communications, organizational relationships, and accountability.

The completion of PLN-3763 at MFC resulted in significant improvements to the level of radiological control and safety. Radiological work procedures were revised to improve consistency and radiological controls were better integrated into work documentation. Work resumed after approximately 3 months and significant effort was made to accomplish as much of the mission work as possible in a safe manner resulting in high-quality products. The lessons learned from this effort were also leveraged LaboratoryWide, through the implementation of PLN-3762. This plan's improvement actions focused on four primary areas: (1) work control and planning, (2) radiological work, (3) organizational effectiveness, and (4) contractor assurance.

Several independent assessments by INL and DOE have validated that these plans have resulted in improved performance, in particular the positive effects of Laboratory-Wide implementation of a formal documented Management Observation Program (MOP). The centerpiece of the plan's actions to improve organizational effectiveness is increased management presence and engagement in the field, which has led to reinforcement of standards for performance and in several cases, has resulted in identifying and correcting precursors to events. INL conducted two assessments for PLN-3762 and PLN-3763 in July 2011. The latter assessment determined that PLN-3763 was effective in achieving its aim of allowing safe resumption of radiological work at MFC. The assessment of PLN-3762 was designed as an interim or midcourse check to determine whether actions had begun having the intended effect and were showing indications of sustainability. This assessment concluded that the actions of the plan were implemented, had resulted in improvement, and that continued effort to make them sustainable should produce the intended results. DOE performed an assessment in August and September of the effectiveness of PLN-3762 and concluded that the plan to date was marginally effective - the actions of the plan had been implemented and resulted in improvement in work control, radiological control program and execution, organizational effectiveness, and Contractor Assurance effectiveness with additional effort needed to produce sustainability and improve the consistency of application of INL work processes. DOE also performed an assessment of the INL Radiological Protection Program in June and concluded that the program was adequately implemented. 
These assessments and event data indicate that the actions from PLN-3762 and PLN-3763 have produced positive results, but have not completely eliminated incidents; for example, there have been events such as the recent radiation exposure incident at Materials and Fuels Complex (MFC), the recent burn from an unfocused laser beam at Specific Manufacturing Capability (SMC), the low level drain down at the Advanced Test Reactor (ATR), and inadequate pre-operational cooling supply valve line up checks at the Neutron Radiography Reactor (NRAD). In addition to continuing efforts to complete the actions of PLN-3762, which are focused primarily on maturing and sustaining the initial actions, INL management has kicked off a "sustained operational improvement" initiative to leverage the success of these plans and drive continual improvement, with the ultimate goal of establishing lasting operational excellence at the Laboratory. This long-term initiative began early in FY 2012 and has aggressive goals for significant sustained improvement.

A new leadership team has been created at MFC to help better understand the mission and how each individual contributes to the success of INL. Facility availability for research is a priority and is being improved through better planning and prioritization of maintenance activities. Continual organizational and process improvements are occurring through the MFC leadership by the Barrier Removal Team and plan of the day meetings. Overall, communications have significantly improved and teamwork is a central theme relating to the accomplishment of the mission. There is a newfound bias for action, emphasizing accountability and ownership that is leading to improved performance.

The INL MOP. The MOP is a key component of the INL Work Control Corrective Action Plan (PLN-3762) to improve organizational effectiveness and establish excellent and sustainable execution of work at INL. The MOP applies to managers and supervisors at all levels who direct work activities performed by INL personnel and/or subcontractors.

The MOP is intended to promote regular and purposeful management presence in areas where employees perform work with an intended outcome to dialogue with employees and understand risks and improve safety, security, and performance. The MOP reinforces ISMS Core Functions and Guiding Principles by having management

- Observe all aspects of the work activities including planning, work execution, and pre- and post- job activities

- Include discussions with employees that reinforce management expectations, recognize good performance, correct undesirable behaviors, build trust between managers and employees, and develop positive relationships with employees

- Jointly evaluate work processes to identify successes, weaknesses, barriers, risks, and potential errors

- Resolve conditions or remove barriers that hinder the organization from achieving its goals and identifying opportunities to improve processes and outcomes

- Use the INL Issues Management System for documenting identified problems, improvement opportunities, strengths, and noteworthy practices.

MOP Planning and Approving. PLN-3762 reinforced INL line management accountability, management system ownership, and governance processes via the implementation of the MOP. Leadership Management Team (LMT) members and Management System Leads (MSL) developed the methods and approach that were the most appropriate for meeting the needs of their organization/management system. The LMT/MSL then presented their strategy (e.g., approach and implementation, metrics, measurements to monitor execution and evaluate effectiveness) to their appropriate INL Governance Council for critical review and final approval. Once in place, each LMT/MSL tracked and trended observation results and other data related to management systems and organization performance and reported periodically to their council for review and feedback. The analysis included, as a minimum: 
- Notable issues identified and actions taken to resolve the condition

- Notable process improvements

- Notable process or employee recognitions

- Tracking of observation results and notable changes in work environment and employee engagement

- Potential trends that need management attention and/or additional evaluation.

MOP Results and Reporting. The methods used to implement management observations by organizations and management systems varied based upon needs and strategic objectives. Discussion and feedback provided to LMT members and MSLs when presenting their approach helped ensure that the strategies and approach being used met the requirements of the MOP and facilitated the intended outcome. It was during these self-critical evaluations that heightened attention was focused on (a) changing behaviors and expectations and not just a rededication of efforts, (b) training and mentoring for managers in order to execute effective observations, and (c) balancing the correction of undesirable behaviors with developing positive relationships with employees. As a result, the responsible LMT/MSL was able to revise and improve their strategy and methods for management observations.

Quarterly evaluations are performed by the applicable management system owners to monitor and report performance of line management engagement and work observations as part of the assurance activities and assurance portfolios. Numerical results presented to the INL Governance Councils included the number of management observations performed, INL Corrective Action Management System (ICAMS) entries based on observations, average observations per manager, types/binning of behaviors (positive, needs improvement, at-risk), identified deficiencies, organizational engagement, trends and leading indicators, and issues management. Observation results have included some increased receptivity by workers to being observed while conducting work, improved housekeeping practices, evaluation of personal protective equipment (PPE) practices, and increased peer checking.

INL Independent Coaching Team. An important component of the MOP is the INL Independent Coaching Team. One of its main goals is to provide senior INL leadership with an independent evaluation of the progress of institutionalizing standards and expectations for management engagement in work planning and execution, as well as worker execution of standards of work control and radiological protection. The coaching team provides an important secondary function of real-time feedback and coaching on engagement and performing good observations where these behaviors are most important in the field. The Teams' results are also monitored through the INL governance process, in this case by the Operations Council, which received reports in June and October.

Results from the independent coaching team included:

- Coaching Reports - The who, what, where, when, and how for each coaching session. Reports describe the discussions that took place during the coaching session, how conversations and interactions proceeded, and the suggestions and recommendations to improve the process

- Employee interactive observations survey — analysis to ascertain their thoughts and understanding of Interactive Observations

- Coaching sessions and analysis - Monitoring the number of planned coaching sessions by facility, the actual number completed, and feedback from coaches and participants

- Lessons Learned and Recommendations - Sharing approach and effective methodologies and sharing strategies to improve coaching based on experience.

Change Management. INL management identified an opportunity to improve consistency in effectively developing and implementing strategic change initiatives; examples included High 
Performance Workplace, MFC changes, Next Generation Business Model, and the Self-Select Program. Clear expectations for implementing BEA-wide change management techniques for FY 2012 are being established, modeled, and reinforced whenever a strategic change initiative (i.e., enterprise-wide, high impact, and moderate to high risk) is pursued.

MOP Continuous Improvement and Sustainment. It is the intent of the INL to sustain and continually improve the use of management observations. INL developed a maturity and sustainment model based on reviews of the results of the initial MOP results, which established criteria against which the MOP can be evaluated. These criteria include level of participation, number and types of deficiencies found as a results of the observations, the quality of observations (e.g., sophistication, level of engagement, self-critical nature), changes in receptiveness, changes in behaviors, improved work habits and morale, and trending data. INL management will use this Maturity Path tool to periodically monitor and evaluate its own commitment to and effectiveness of the MOP.

MOP Summary. The MOP has so far proven to be very successful in reinforcing the ISMS core functions and guiding principles and in establishing excellent and sustainable execution of INL's integrated work control. A regular and purposeful management presence in the field has been developed with an intended outcome to understand risks and improve safety, security, and performance. The flexible approach to develop MOP plans has allowed the organizations to meet specific or unique needs of their workers and mission. The INL Independent Coaching Team was a valuable tool in mentoring and training managers. Current plans and strategies to maintain the MOP will help ensure its continual improvement and sustainment.

Contractor Assurance System (CAS) Implementation. In FY 2011, the INL CAS has seen improvements in the use and ownership of the system and tools. This is especially evident in improvements in the planning and execution of risk-informed assurance activities, the increased use of high-volume/low threshold issues management system and INL leadership and engagement in ensuring the effectiveness of corrective actions. Notable examples included the successful rollout of a management observation program (discussed previously), broader establishment of CARBs - driven by PLN-3762, and the formation of a cross-organizational project team to institute more global improvements to the issues management program.

This has resulted in INL witnessing a dramatic increase in documented evidence of leadership engagement with staff in the field. Significant effort has been put into collectively designing programs in a way that will provide INL-wide trending data related to the work control process execution and better enable targeted corrective actions and process improvements. Quarterly reporting of management observations and other assurance activity to the INL governance councils has resulted in broader and increased engagement in understanding the health of the INL and is driving improvements in performance measuring.

The CAS elements of cause analysis, event investigations, and critiques have improved with respect to their quality, rigor and effective mentorship. This was recently seen in the depth and breadth of the recent Low Level ATR Reactor Vessel investigation, causal analysis, and Corrective Action Plan (CAP). The increasing visibility and attention to the corrective action process by management has been noteworthy and will be continuously reinforced in FY 2012.

Performance review meetings held with all directorates in FY 2011 included discussions of CAS expectations. Topics included the importance of linking risk mitigation to specific assurance activities, understanding required assurance activity expectations, ensuring appropriate entry of issues into the Issues Management Tracking System, improving the timeliness of lessons learned reviews and usage of the lessons learned database, and the reporting of performance analysis through the quarterly assurance reports. 
Additional FY 2011 CAS accomplishments included:

- Quarterly Portfolio Status reports providing current status, performance, and emerging risks reported to Governance Councils

- Contractor Assurance Dashboards are more widely used by governance councils

- Assessments continue to improve in quality and focus on performance

- Integrated Assessment System database upgrades (link to ICAMS and Electronic Documents Management System [EDMS] records, requires risk-rank field)

- MOP implementation (all managers, all organizations)

- Cross organizational team efforts for issues management

- Trending, discipline code usage, training, reporting, process integration

- Implementation of Research and Education Campus (REC) and Central Facilities Area (CFA) CARBs

- Multidiscipline participation in CARBs across the Laboratory

- Revision of INL critique process to include Extent of Conditions and lessons learned

- Improvement in quality of formal causal analyses

- Trending and analysis guide developed

- ICAMS classroom training developed

- Piloted training for CAP development.

The INL CAS continues to face a challenge of promoting the right balance of assurance activity that enables INL to find, understand, and correct deficiencies; and improve performance while ensuring organizations are not burdened with nonvalue-added activity. The principle of reasonable assurance recognizes that management controls must be both effective and efficient and applied in a manner commensurate with the risks, mission, and activities of the implementing organizations. It recognizes that the potential for deficiencies, errors, or events remains, but that upon discovery, management action will be undertaken promptly to address shortfalls, omissions, or errors in order to minimize the impact of such events and to learn from those events so as to drive improvement. Sustainment of CAS improvement actions, such as increased management engagement in the field, is critical to the effective execution of long-term solutions to CAPs.

Issues Management and Tracking System. The ICAMS is the INL-standard comprehensive tool for problem reporting, tracking, and resolution. ICAMS

- Serves primarily as a key tool for continuous improvement of INL processes, procedures, and work execution in keeping with guiding principles of ISMS

- Provides a graded approach to resolving problems identified through assessments, occurrences, or by management and employee observations

- Is a powerful management tool, which provides:

- A way to capture high volume, low threshold observation data

- Tracking and trending analysis so managers can identify and correct smaller issues before they can turn into larger problems

- A way to ensure that the issues needing attention reaches the right management and/or organizations at INL. 
Risk-informed assurance activities are planned, executed, and closed out in a timely fashion; are identifying substantive issues; and are followed by appropriate and timely corrective actions. Assurance tools are strategically utilized to assess and monitor any identified or potential areas of risk. Notably are the timely use of targeted management observations to validate behavior changes associated with corrective actions, and the initiation of in-process effectiveness reviews to provide feedback and facilitate any corrective action course corrections or enhancements. Management has documented increased oversight and review of assurance products in Management Review Committees and CARBs. The sitewide self-identification of issues ratio more than doubled in FY 2011. The percentage of scheduled assessments completed reached $90 \%$ (above the goal of $80 \%$ ), with an average of $86 \%$ of the activities associated with an identified risk.

The effectiveness of safety management programs, including those credited in the safety bases for nuclear facilities, are adequately assessed. Each FY 2011 monthly report included examples of satisfactory compliance and effectiveness for safety management systems. These data are captured in the Integrated Assessment System database and the ICAMS. Safety Management Program assessments have provided substantial issues and actions leading to overall continuous performance improvement and enhanced safety.

Continuous improvement in the implementation of a high volume, low threshold issues management system is evident in accordance with an implementation plan adopted by the pilot working group. Use of high volume, low threshold issues management has steadily matured through FY 2011, with annual usage commensurate with nuclear industry metrics obtained from the Corrective Action Program Owner's Group. The initiation of a structured MOP has greatly contributed to the relevance of the data being collected in the ICAMS. Fundamental elements of cognitive trending are being demonstrated and acted upon at facilities with high activity levels. Where activity is lower, self critical observations with associated individual corrective actions are in evidence and documented in ICAMS.

Improvement is still needed in entering issues into the ICAMS for tracking, management and resolution and timely completion of ICAMS causal analysis and planning phases. An Issues Management Improvement Implementation Plan to provide continuous improvement in the implementation of a high volume, low threshold issues management system was developed in FY 2011 and focused on the areas of training, trending, discipline code structure, and integration. These primary areas were determined through an external assessment (IAS 101959).

An assessment based on recommendations from IAS 101959 is being conducted to close-out FY 2011 issues management improvement actions and evaluate the state of Issues Management with respect to the original improvement plan gap areas.

Operational events are adequately critiqued, reported, and investigated, with appropriate and timely corrective actions. Appropriate analysis and trending is performed and lessons learned are applied sitewide. The quality of event investigation and organizational learning was a strong focus of INL leadership and INL Governance Councils. Additional CARBs have been established through formal charters and have provided oversight of contractor assurance products; including corrective actions, action plans, assessment results, extent of conditions, and event analysis resulting in continuous quality improvement. Leadership demonstrated active management of CAPs by providing priority guidance and adequate resources. Extent of condition assessments has provided valuable insight for the practical application of lessons learned sitewide. Strategic use of in-process effectiveness assessments and trending of targeted management observations have validated corrective action effectiveness, corrective action sustainability, and provided indication of desired behavior changes.

All assessment results, performance metrics, plans, schedules, issues management data, and other CAS products are readily available for review and analysis to DOE-ID. All CAS products were made 
available for review and analysis by DOE. Any issues or requests for data were resolved in a timely manner through communications with system experts, email, and one-on-one meetings with product owners.

Achieving a Safety Breakthrough. Improving our injury and illness rates continues to present challenges requiring aggressive actions on multiple fronts to impact the bottom line. INL is making progress, and there are successes to celebrate. Of the 19 major organizations within the laboratory, 10 completed FY 2011 without incurring an Occupational Safety and Health Act (OSHA) recordable injury or illness, and 13 completed FY 2011 without incurring a DART case. Additionally, in early July, employees at the entire ATR Complex completed 1 full year without incurring an OSHA recordable injury or illness. The resulting INL FY 2011 OSHA recordable case rate of 0.96 represents an improvement of almost 30\% compared to the FY 2010 rate of 1.37 , and is over $19 \%$ better than the FY 2004 baseline rate of 1.19. The FY 2011 INL DART case rate of 0.50 represents an improvement of over 32\% compared to the FY 2010 rate of 0.74 , and is $18 \%$ better than the FY 2004 baseline rate of 0.61 . This year's injury/illness rates represent one of INL's best years. We must break past this point for continued progress. The causes of injury and illness, the challenges they create, and the fact that unique mitigations are the key to preventing injury and illness are understood. A focus on heightened staff attention and awareness, and a Fitness for Duty initiative designed to ensure employees are physically capable and ready to perform their job tasks are improving INL's performance. An increased emphasis on communicating with employees and taking actions to reinvigorate the management observation process are producing results. Managers have been challenged to increase their presence at worksites and increase safety-related interactions with employees. 


\section{A-2 ANNUAL EFFECTIVENESS REVIEW SCOPE AND APPROACH}

INL strives to continuously improve by focusing assessments and other assurance activities on the elements and successful implementation of ISM core functions and guiding principles. This review of FY 2011 ISM effectiveness evaluated ISM-relevant activities and assessments and summarized their results as related to the effective implementation of the five core ISM functions and eight guiding principles.

Figure A-1 summarizes the assurance activities performed at the INL in FY 2011 and the resulting ICAMS actions that resulted from those activities.

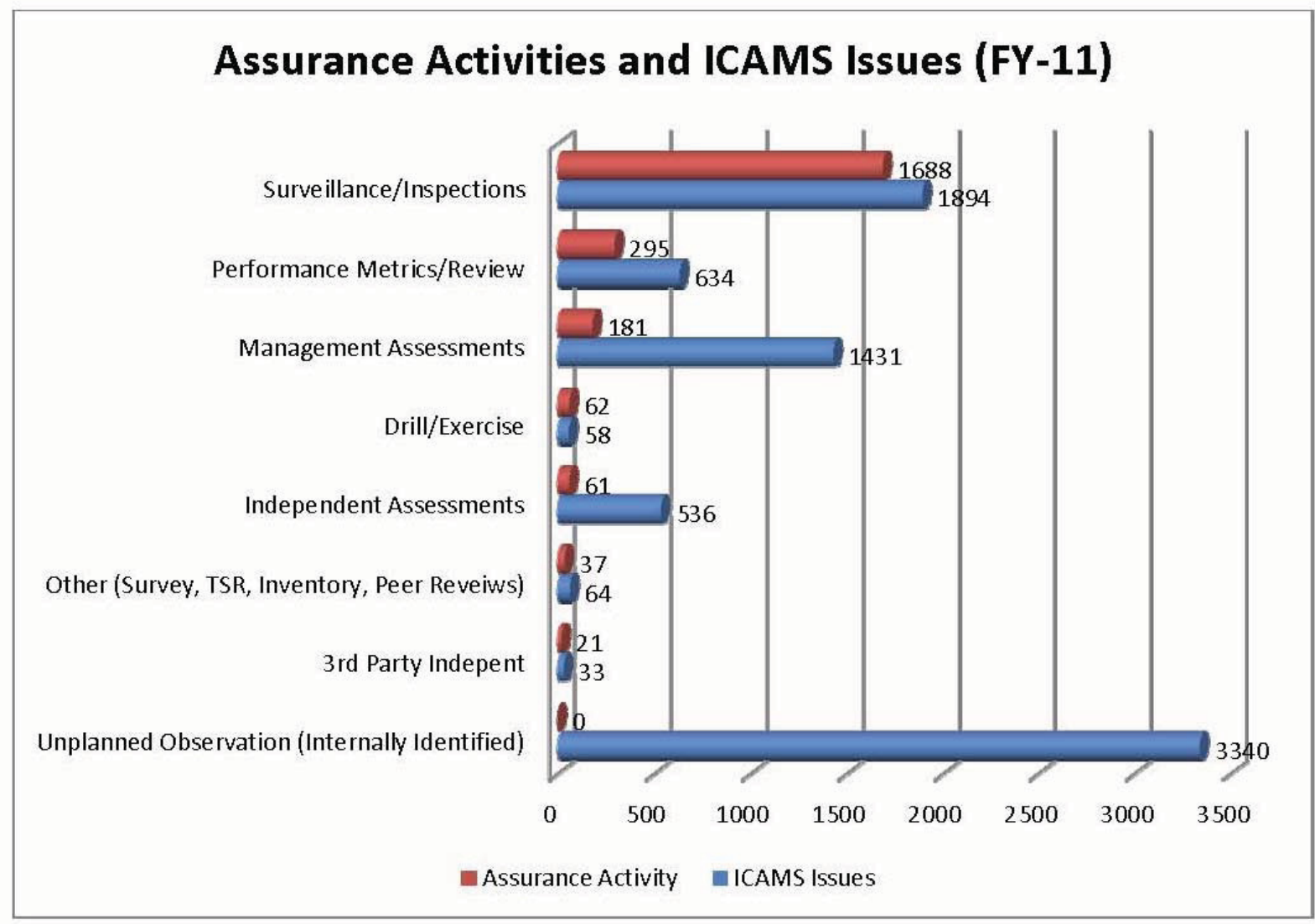

Figure A-1. Assurance activities and ICAMS issues summary for FY 2011.

INL engaged in numerous assurance activities as depicted in Figure A-1, and they resulted in a significant number of corrective actions which were entered into the ICAMs database to be tracked to completion with the intent to improve processes and correct deficiencies.

An in-depth evaluation of several high- and low-level assessment activities was performed to determine the effectiveness of ISMS implementation. The results are displayed in Table A-3. This table relates the assessment activities to the applicable eight guiding principles and five core functions. The following descriptor will assist in the interpretation and understanding of the table:

- Selection Process: 
- Six of the more high level and visible assessments that were conducted in FY 2011 associated with events

- Six randomly selected assessments that were performed in FY 2011

- Identified and reviewed all ICAMS entries associated with each of the assessments.

- Review Process:

- Reviewed each assessment and ICAMS entry and identified which, if any, of the eight guiding principles and five core functions were addressed

- The chart represents the activity level and area of ISMS core functions and guiding principles that the assessments were engaged in

- The number in each box - represents the number of times the ICAMS activities for that assessment referred to a specific core function or guiding principle

- Blue - represents which of the core functions and/or guiding principles were discussed in the assessment.

Table A-3. Assessment activities for the applicable eight guiding principles and five core functions.

\begin{tabular}{|c|c|c|c|c|c|c|c|c|c|c|c|c|c|c|}
\hline \multicolumn{2}{|c|}{ Assessment Information } & \multicolumn{5}{|c|}{ Core Functions } & \multicolumn{8}{|c|}{ Guiding Principles } \\
\hline $\begin{array}{c}\text { Assessment } \\
\#\end{array}$ & Assessment Name & 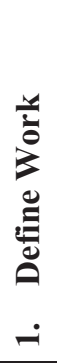 & 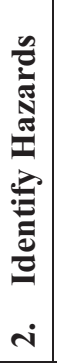 & 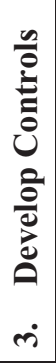 & 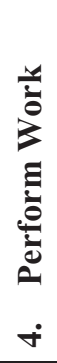 & 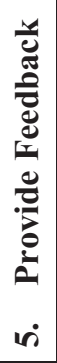 & 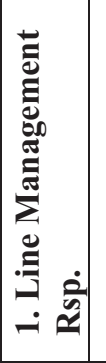 & 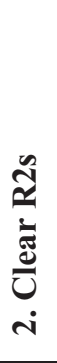 & 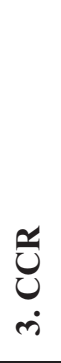 & 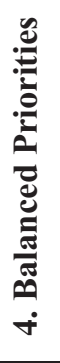 & 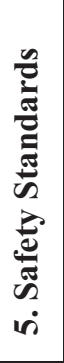 & 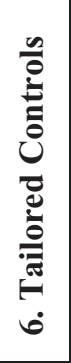 & 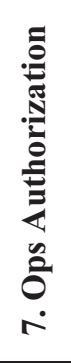 & 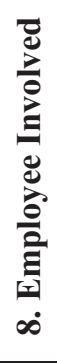 \\
\hline \multicolumn{15}{|c|}{ Selected Assessments } \\
\hline IAS111875 & $\begin{array}{l}\text { Combined } \\
\text { Assessment of INL } \\
\text { Management } \\
\text { Systems and } \\
\text { Portfolios } \\
\end{array}$ & & 2 & 1 & & 1 & 2 & 3 & 2 & 2 & 1 & & & \\
\hline IAS112085 & $\begin{array}{l}\text { Interim Effectiveness } \\
\text { Assessment of INL } \\
\text { Work Control } \\
\text { Corrective Action } \\
\text { Plan, PLN-3762 }\end{array}$ & 2 & & 1 & 1 & 1 & 1 & & 1 & & 1 & 3 & & 1 \\
\hline IAS111769 & $\begin{array}{l}\text { INL Radiological } \\
\text { Work Planning third- } \\
\text { party independent } \\
\text { assessment }\end{array}$ & 4 & 4 & 5 & & & & 1 & 2 & & 9 & 9 & & 2 \\
\hline IAS112098 & $\begin{array}{l}\text { Effectiveness } \\
\text { Assessment of the } \\
\text { Completion of the } \\
\text { "MFC Recovery } \\
\text { Plan," PLN-3763 }\end{array}$ & 1 & 1 & 3 & 2 & 2 & 3 & 2 & 2 & & 3 & 2 & 1 & 2 \\
\hline IAS111861 & $\begin{array}{l}\text { Assessment of } \\
\text { Causal Factors for } \\
\text { INL RadCon and } \\
\text { Work Control Events }\end{array}$ & 2 & & & 2 & 1 & 1 & 1 & & 1 & 1 & & 1 & \\
\hline
\end{tabular}




\begin{tabular}{|c|c|c|c|c|c|c|c|c|c|c|c|c|c|c|}
\hline \multicolumn{2}{|c|}{ Assessment Information } & \multicolumn{5}{|c|}{ Core Functions } & \multicolumn{8}{|c|}{ Guiding Principles } \\
\hline $\begin{array}{c}\text { Assessment } \\
\#\end{array}$ & Assessment Name & ن & 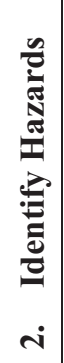 & 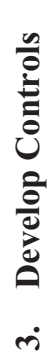 & 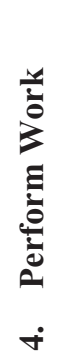 & 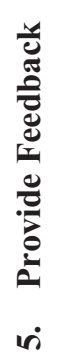 & 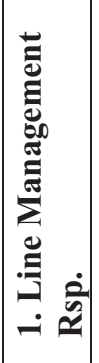 & 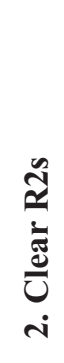 & 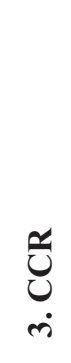 & 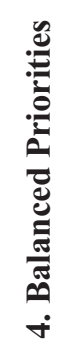 & 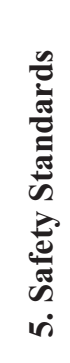 & 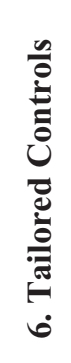 & 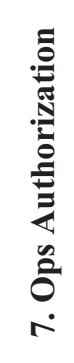 & 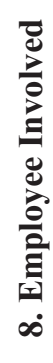 \\
\hline IAS112094 & $\begin{array}{l}\text { Risk Identification } \\
\text { and Use of Risk } \\
\text { Tools }\end{array}$ & & 1 & & 1 & 1 & 1 & 2 & & 1 & 1 & 1 & & 2 \\
\hline \multicolumn{2}{|c|}{ Random Assessments } & & & & & & & & & & & & & \\
\hline IAS111776 & $\begin{array}{l}\text { Safety System } \\
\text { Assessment of the } \\
\text { Cell Exhaust System } \\
\text { at the MFC Fuel } \\
\text { Conditioning Facility } \\
\text { (FCF) }\end{array}$ & & & 4 & 2 & 1 & 1 & & & & 4 & 5 & & 2 \\
\hline IAS101883 & $\begin{array}{l}\text { F\&SS } \\
\text { Manufacturing } \\
\text { Services Work } \\
\text { Management } \\
\text { Implementation }\end{array}$ & & 6 & 5 & 2 & 5 & 2 & 3 & & 2 & 6 & 4 & 1 & \\
\hline IAS111820 & $\begin{array}{l}\text { Verification and } \\
\text { Validation of INL } \\
\text { Project Management } \\
\text { Action Item Closure }\end{array}$ & & & & 3 & 2 & & 2 & & 1 & & & 1 & \\
\hline IAS111862 & $\begin{array}{l}\text { Independent } \\
\text { Assessment of the } \\
\text { Quality Assurance } \\
\text { Program at SMC }\end{array}$ & & & 2 & 4 & 6 & 3 & 1 & & 1 & 5 & 2 & & 2 \\
\hline IAS112187 & $\begin{array}{l}\text { Safety Rod Safety } \\
\text { System Assessment }\end{array}$ & 1 & & 3 & 1 & 2 & & 1 & & & 2 & 3 & & 1 \\
\hline IAS101906 & $\begin{array}{l}\text { Assessment of MFC } \\
\text { Production Control } \\
\text { Processes }\end{array}$ & 4 & & & 2 & & 1 & 2 & 1 & 1 & & & 1 & \\
\hline
\end{tabular}


The above information indicates a fairly balanced picture of ISMS core functions and guiding principles as being embedded in INL's assurance processes and activities.

Table A-4, Table A-5, and Table A-6 lists a sample of causal analyses, external assessments, and internal assessments with the areas of ISMS that were addressed in their corrective actions. The corrective actions in all three categories were heavily weighted toward the core functions of "Define the Scope of Work," "Analyze the Hazards," and "Develop and Implement Hazard Controls." This aligned very well with the risk that the Laboratory had identified for work planning and work control and the need to improve these areas. The majority of the Guiding Principles corrective actions were related to Principle 2 - Clear Roles and Responsibilities, Principle 3 - Competence Commensurate with Responsibilities (CCR), and Principle 6 - Hazard Controls Tailored to Work Being Performed. The level of emphasis in both the core functions and the guiding principles reflects the recognized risk and emphasis on improving the areas of work planning, hazard mitigation and control of work.

Table A-4. Cause analysis results.

\begin{tabular}{|c|c|c|}
\hline \multicolumn{3}{|l|}{$\begin{array}{c}\text { Cause Analysis Results } \\
7 \text { Analyses, } 61 \text { Corrective Actions (avg } 8.71 \text { per Analysis) }\end{array}$} \\
\hline Area & \# & $\%$ \\
\hline Define the Scope of Work & 21 & $29 \%$ \\
\hline Analyze the Hazards & 11 & $15 \%$ \\
\hline Develop and Implement Hazard Controls & 24 & $33 \%$ \\
\hline Perform Work within Controls & 4 & $6 \%$ \\
\hline \multirow[t]{2}{*}{ Provide Feedback and Continuous Improvement } & 12 & $17 \%$ \\
\hline & 72 & \\
\hline Guiding Principle 1 -Line Management Responsible for Safety & 8 & $12 \%$ \\
\hline Guiding Principle 2 -Clear Roles and Responsibilities & 16 & $23 \%$ \\
\hline Guiding Principle 3 -Competence Commensurate with Responsibilities (CCR) & 12 & $17 \%$ \\
\hline Guiding Principle 4 -Balanced Priorities & 1 & $1 \%$ \\
\hline Guiding Principle 5 -Identification of Safety Standards and Requirements & 4 & $6 \%$ \\
\hline Guiding Principle 6 -Hazard Controls Tailored to Work Being Performed & 22 & $32 \%$ \\
\hline Guiding Principle 7 -Operations Authorization & 0 & $0 \%$ \\
\hline \multirow[t]{2}{*}{ Guiding Principle 8 -Employee Involvement } & 6 & $9 \%$ \\
\hline & 69 & \\
\hline
\end{tabular}


Table A-5. External assessments results.

\begin{tabular}{|c|c|c|}
\hline \multicolumn{3}{|l|}{$\begin{array}{l}\text { External Assessments Results } \\
3 \text { Assessments, } 24 \text { Corrective Actions (avg } 8 \text { per assessment) }\end{array}$} \\
\hline Area & \# & $\%$ \\
\hline Define the Scope of Work & 13 & $33 \%$ \\
\hline Analyze the Hazards & 9 & $23 \%$ \\
\hline Develop and Implement Hazard Controls & 12 & $30 \%$ \\
\hline Perform Work within Controls & 2 & $5 \%$ \\
\hline \multirow[t]{2}{*}{ Provide Feedback and Continuous Improvement } & 4 & $10 \%$ \\
\hline & 40 & \\
\hline Guiding Principle 1 -Line Management Responsible for Safety & 3 & $9 \%$ \\
\hline Guiding Principle 2 -Clear Roles and Responsibilities & 15 & $43 \%$ \\
\hline Guiding Principle 3 -Competence Commensurate with Responsibilities (CCR) & 1 & $3 \%$ \\
\hline Guiding Principle 4 -Balanced Priorities & 2 & $6 \%$ \\
\hline Guiding Principle 5 -Identification of Safety Standards and Requirements & 7 & $20 \%$ \\
\hline Guiding Principle 6 -Hazard Controls Tailored to Work Being Performed & 7 & $20 \%$ \\
\hline Guiding Principle 7 -Operations Authorization & 0 & $0 \%$ \\
\hline \multirow[t]{2}{*}{ Guiding Principle 8 -Employee Involvement } & 0 & $0 \%$ \\
\hline & 35 & \\
\hline
\end{tabular}

Table A-6. Internal assessments results.

\begin{tabular}{|c|c|c|}
\hline \multicolumn{3}{|l|}{$\begin{array}{l}\text { Internal Assessments Results } \\
6 \text { Assessments, } 38 \text { Corrective Actions (avg } 6.33 \text { per assessment) }\end{array}$} \\
\hline Area & \# & $\%$ \\
\hline Define the Scope of Work & 3 & $25 \%$ \\
\hline Analyze the Hazards & 0 & $0 \%$ \\
\hline Develop and Implement Hazard Controls & 4 & $33 \%$ \\
\hline Perform Work within Controls & 2 & $17 \%$ \\
\hline \multirow[t]{2}{*}{ Provide Feedback and Continuous Improvement } & 3 & $25 \%$ \\
\hline & 12 & \\
\hline Guiding Principle 1 -Line Management Responsible for Safety & 3 & $18 \%$ \\
\hline Guiding Principle 2 -Clear Roles and Responsibilities & 8 & $47 \%$ \\
\hline Guiding Principle 3 -Competence Commensurate with Responsibilities (CCR) & 1 & $6 \%$ \\
\hline Guiding Principle 4 -Balanced Priorities & 1 & $6 \%$ \\
\hline Guiding Principle 5 -Identification of Safety Standards and Requirements & 0 & $0 \%$ \\
\hline Guiding Principle 6 -Hazard Controls Tailored to Work Being Performed & 4 & $24 \%$ \\
\hline Guiding Principle 7 -Operations Authorization & 0 & $0 \%$ \\
\hline \multirow[t]{2}{*}{ Guiding Principle 8 -Employee Involvement } & 0 & $0 \%$ \\
\hline & 17 & \\
\hline
\end{tabular}


Figure A-2 depicts the corrective action activities that resulted from seven causal analysis reports, three external assessments, and six internal assessments (detailed in the tables above) and sorted into the applicable eight guiding principle categories.

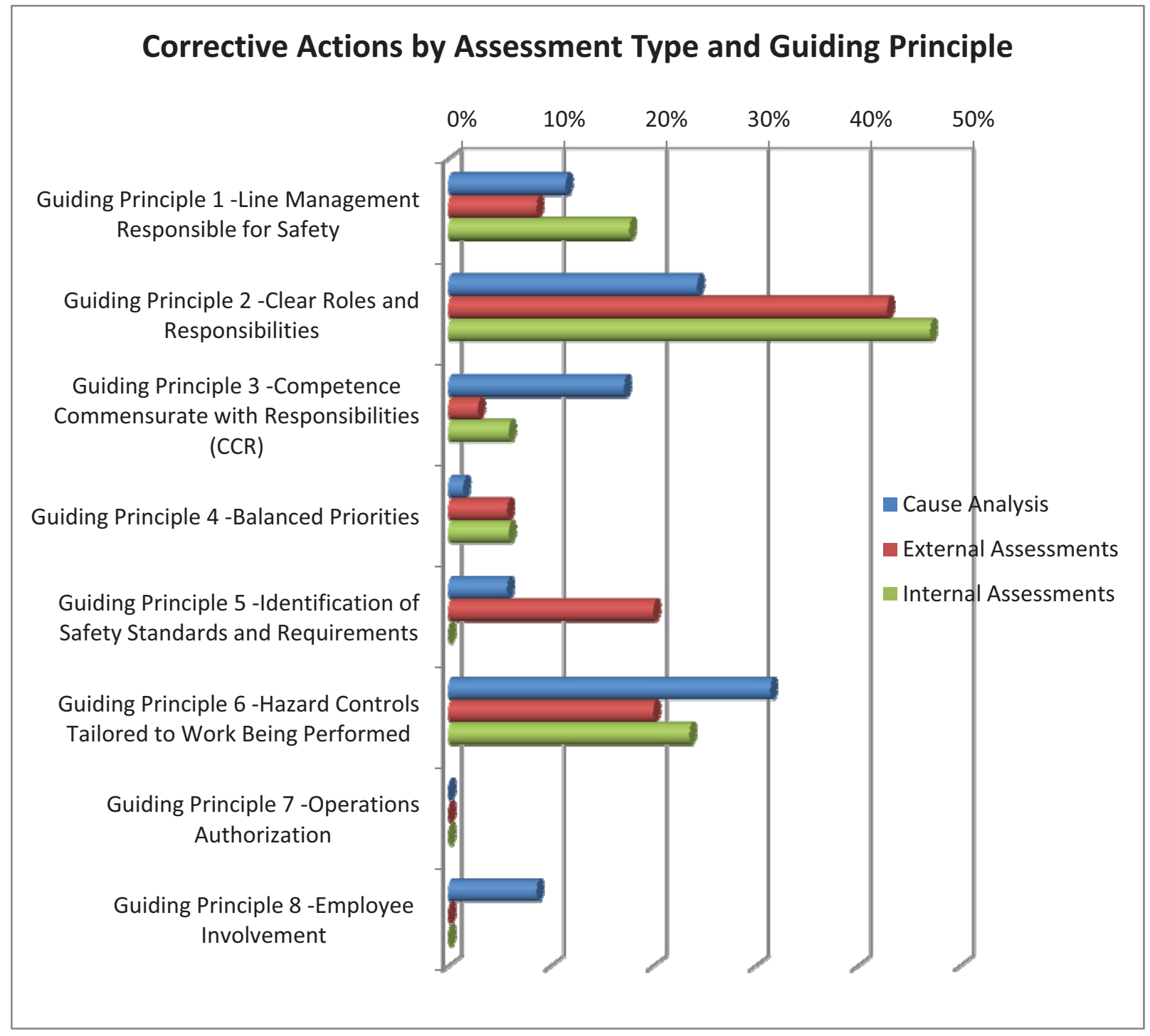

Figure A-2. Corrective actions by assessment type and guiding principle.

Figure A-3 depicts the corrective action activities that resulted from seven causal analysis reports, three external assessments, and six internal assessments (detailed in the tables above) and sorted into the applicable five core function categories. 


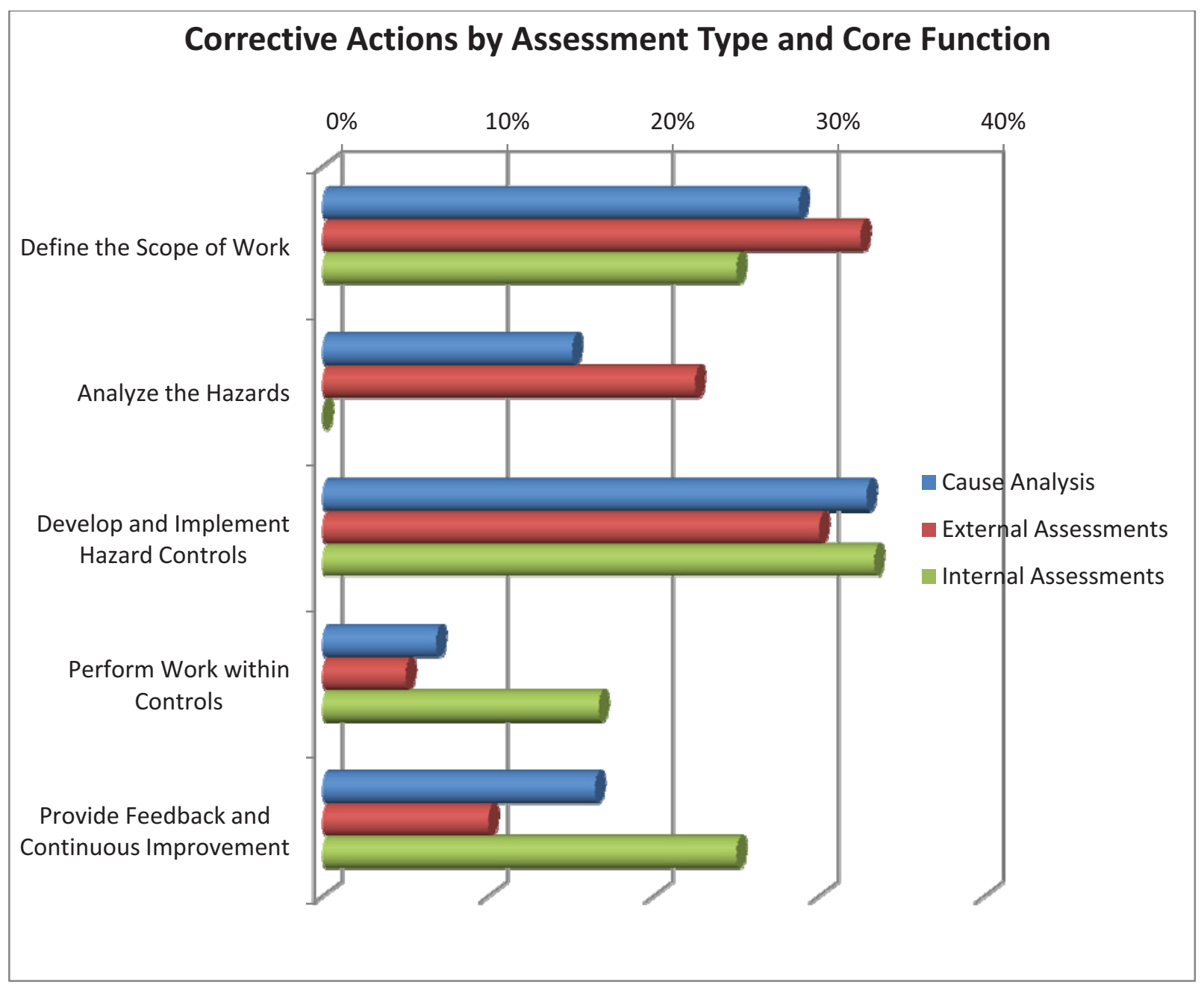

Figure A-3. Corrective actions by assessment type and core function.

An extensive review of these assurance activities concluded the following:

- Guiding Principles results show the largest percentages of effort are focused in the areas of "Clear Roles and Responsibilities" and "Hazard Controls Tailored to Work Being Performed." "Line Management Responsible for Safety" also had a fairly high showing. This information was pulled from the corrective actions performed as a result of the assessment. This would indicate that a large portion of what is being corrected falls into the preparation activities prior to performing the work.

- Core Function results show the largest percentages of effort are focused in the areas of "Define the Scope of Work," "Analyze the Hazards" and "Develop and Implement Hazard Controls." The information pulled from corrective action results would indicate that a large portion of what is being corrected falls into the preparation activities prior to performing the work.

- It appears that defining the work and ensuring that there are applicable hazard controls in place are the areas INL should consider applying more focused resources and efforts prior to performing work. The number of corrective actions involving core function 4 "perform work within controls" was fairly low also pointing to efforts need to be focused on safely preparing to do the work. The performance of the work can be done safer if the ISMS functions are implemented effectively early and followed. 
- None of the corrective actions addressed the Guiding Principle of "Operations Authorization," although this was a limited sampling, some results related to this principle would be expected. This might indicate that this principle should be targeted with some assurance activities in FY 2012.

- A key component of defining and achieving "Competence Commensurate with Responsibilities (CCR)" is in the area of training. Training was repeatedly mentioned as needing to be enhanced, improved, created, or enforced. This was identified most often in the Cause Analysis Results. A comprehensive assessment of INL training programs and the improvements that are being made as a result are discussed in detail in section 6.3.7.

\section{A-2.1 Summary}

Analysis of the "Core Functions" and "Guiding Principles" corrective actions, indicate that our largest opportunity for improvement is in the preparation activities (i.e., defining the work, identifying the hazards) prior to releasing and performing the work. It should be noted that during the review it was noticed that several examples of the failures in defining the work were a result of scope creep.

Even though corrective actions are generally lagging indicators, in this case, the activities and attention devoted to fixing the areas of defining, planning, and mitigating the work demonstrates they are good leading indicators signifying effort that should be emphasized during the processes prior to work being performed. Ensuring that training, responsibilities, and expectations are explained and understood, a well defined scope is in place, and that issues associated with the work to be performed have been addressed and resolved prior to work being performed are critical for the success of completing work safely.

At the beginning of FY 2012, INL experienced an airborne event that potentially exposed 16 workers. The cause analysis and accident investigation will likely indentify further improvement opportunities for ISMS. It also serves as an indicator that ISMS needs improvement. 


\section{A-3 CORE FUNCTION ONE - DEFINE THE SCOPE OF WORK}

Core function one, define the scope of work, is effectively implemented. Work scope at the laboratory level is defined by the INL mission, which guides the strategic actions, resources, and infrastructure activities of the Laboratory. Priorities are balanced to safely accomplish the mission. A well-defined scope of work at the Laboratory level is essential for proper alignment and balancing of program, facility, and infrastructure activities. Proposed work scope for work to be performed at the Laboratory is aligned with the strategic vision and screened for risk prior to requesting funding.

\section{A-3.1 Assessment of Radiological Work Planning}

On January 7, 2011, the suspension of all work requiring a radiological work permit process at MFC and Idaho Nuclear Technology and Engineering Center (INTEC) was implemented by MFC senior management due to the identification of broad problems in execution and planning of radiological work. Then a second suspension was initiated for radiological work at MFC on January 21, 2011. The curtailment was called to develop and implement a more in-depth approach for work process reviews and associated corrective actions.

The Laboratory initiated a CAP (PLN-3762) to address the issues of the common cause analyses, DOE reviews, the Consent Order and other events involving radiological work over the previous 2 years.

Radiological work being performed at the MFC facilities was back at near $100 \%$ during the fourth quarter FY 2011 after the MFC shutdown for radiological work that occurred in the second quarter FY 2011.Two recent events handling radiological materials at MFC has caused reason for concern and evaluation of the corrective actions that have taken place. A recent exposure that occurred at the Zero Power Physics Reactor (ZPPR) and a recent incident involving the handling of metallurgical samples in the Hot Fuel Examination Facility (HFEF) Hot Repair Area (HRA), which resulted in a worker receiving an extremity exposure of 3,580 mrem, has suspended all work involving extremity monitoring and all work with transuranics. The full impacts from these events are still being assessed at this time. The INL sponsored an independent assessment of radiological work planning, "IAS111769 - Third-Party Independent Assessment of INL Radiological Work Planning" after the work stoppage in January 2011.

The assessment was commissioned by ES\&H management to review the radiological work planning process at INL and was conducted January 25-27, 2011, using a combination of worker interviews and document reviews. The assessment scope primarily focused on radiological work planning documentation, process, and applicable worker responsibilities associated with MFC operations.

Results: "Marginally Effective" to "Effective." The assessment team provided two issues and nine observations that are currently being addressed. Assessors found that an energetic management team committed to resolving the challenges to the radiological control program has been put in place and is working diligently to institute the corrective actions that should remediate several of the identified observations.

\section{A-3.2 Effectiveness of Completion of MFC Recovery}

An Independent Effectiveness Assessment of the Completion of the MFC Recovery PLN-3763 (IAS112098) was performed to identify the specific tasks necessary to reestablish radiological work at MFC. The path forward outlined by MFC leadership established tailored, consistent, sustainable, and integrated work control and radiological control programs that would facilitate the execution of research, operations, and maintenance work in a safe and compliant manner. 
The team concluded that PLN-3763 corrective actions have had a significantly positive effect at MFC, but more work is remaining. The sustainability of the changes is being addressed via PLN-3762 (see section A-4.1) the team found a number of very positive changes. The changes were dramatic for those on the team who were familiar with MFC prior to the radiological work shut down as presented below:

- Work documents - Work Orders, as low as reasonably achievable reviews and radiological work permits (RWPs) are much improved. A refined focus is on work control documents on specific scopes and hazard controls (including radiological hazards) and less reliance on general hazard control documents. An increased emphasis is on walk-downs, focused reviews and roundtables with a corresponding improvement in the quality of work documents.

- Interviews and observations demonstrated a clear shift of accountability for radiological protection from the radiological controls organization to the individual and a renewed emphasis on planning for radiological hazards. Most workers/staff, supervisors, and managers demonstrated a "healthy sense of uneasiness," recognition, and ownership for radiological hazards.

- Worker and management knowledge of individual extremity doses was very good under the extremity dose tracking program being piloted at MFC.

- Commitment and support for PLN-3762 and PLN-3763 actions were widespread and visible. Senior management support was likewise pervasive and visible. This included support for the MOP, which will be a key aspect in the continued progress and sustainability of the improvements seen to date. 


\section{A-4 CORE FUNCTIONS TWO AND THREE - ANALYZE THE HAZARDS, DEVELOP AND IMPLEMENT HAZARD CONTROLS}

Core functions two and three, analyze the hazards and develop and implement hazard controls, are effectively implemented but needs further improvement. The objective of hazard identification, analysis, and control is the safe accomplishment of the INL mission by eliminating or mitigating hazards to protect the workers, the public, the environment, and INL facilities and programs.

INL has developed a number of viable and proven mechanisms to meet this objective. These mechanisms exist at the Laboratory, facility, and activity levels and have been tailored to the different work functions and work areas of INL. They employ a hierarchy of controls to ensure that hazard exposures are minimized or mitigated. Engineered solutions are the first consideration, followed by administrative controls and personnel protective equipment (PPE).

\section{A-4.1 INL Hazard Identification and Control Processes}

A very high percentage of INL work is completed without issue. The nature of INL work often inherently involves uncertainty and therefore, a higher level of risk. Much of the work with a higher risk level is conducted at MFC. Early in 2010, three separate events that occurred between September 2010 and January 2011 at MFC prompted INL management to voluntarily suspend work there. As discussed in detail in Section 1.4, two CAPs, PLN-3762 and PLN-3763, were developed. PLN-3763 was a short-term plan to enable the safe resumption of radiological work at MFC. PLN-3762 embodied the sustainability of PLN-3763, but was applicable to the entire Laboratory and addressed several broader underlying performance improvement and organizational effectiveness issues. The four main areas of improvement addressed in PLN-3762 were (a) radiological protection program improvements and implementation, (b) work control execution, (c) contractor assurance use and effectiveness, and (d) improvements in organizational effectiveness.

Both INL and DOE have performed assessments, as discussed in section 1.4, of the effectiveness of these significant improvement plans, as well as the progress in improving the Radiological Protection Program. INL's assessments determined that PLN-3763 was effective in achieving its aim of allowing safe resumption of radiological work at MFC, and that PLN-3762 had resulted in improvement and was on track to make the improvements sustainable. DOE's assessment of PLN-3762 concluded that the actions of the plan had been implemented and resulted in improvements in radiological control program and work control execution, contractor assurance and organizational effectiveness, and that additional effort is needed to produce sustainability and improve the consistency of applying INL work processes. DOE also performed an assessment of the INL Radiological Protection program in June 2011 and concluded that the program was adequately implemented. 


\section{A-5 CORE FUNCTION FOUR - PERFORM THE WORK WITHIN CONTROLS}

Core function four, perform the work within controls, is effectively implemented; however, opportunities for improvement exist.

A common cause analysis of radiological control events identified weaknesses in in-field supervision. Expectations for adhering to risk and procedure requirements were not being consistently reinforced by line management during work implementation, which sometimes caused risk to be managed at too low a level within organizations and led to mistakes. This common cause analysis was included in the analysis that produced PLN-3762. Corrective actions are in progress per PLN-3762, and are deemed to be on track as discussed in subsection A-4.1 under IAS112085.

The events and issues were not the result of poor Laboratory work management or radiological control processes or a lack of a process. Rather, the events were rooted in the execution of work, this included physical work activities performed contrary to expectations and where expectations were not expressed or understood clearly, as well as execution of work planning functions that was not in accordance with the intent of the standards in these Laboratory processes. Four main causal factors were identified in the Independent Assessment of Causal Factors for INL Work Management and Radiological Control Events (IAS111861), and are:

- Insufficient understanding, alignment, and engagement of managers with Laboratory leadership expectations and Laboratory-prescribed work processes

- Inadvertent reinforcement of the wrong behaviors

- Ineffective and sometimes incomplete management of change

- Insufficient teamwork and pride of ownership of the Laboratory.

Each of these causal factors was considered in the development of PLN-3762 (see section A-4.1).

INL work is authorized and performed at the Laboratory, facility, and activity levels through formal processes described in PDD-1004. Some measures of work performance include performance in the Safety and Security DOE Regulatory Program, environmental compliance, and radiological control compliance, injuries and illnesses, quality, and nuclear safety. These are discussed in the following subsections.

\section{A-5.1 Safety and Security DOE Regulatory Program}

INL utilizes a centralized issue management tracking program called ICAMS. Potential issues and/or problems entered into ICAMS are categorized based on severity. Entries considered high volume and low consequence are placed in predefined categories that are later reviewed for trends. The remainder of the entries undergo a screening process for identification of noncompliances with nuclear safety requirements contained in 10 CFR 830 and 835 or a noncompliance with worker safety and health requirements contained in 10 CFR 850 and 851 . Those that are screened as noncompliances undergo an additional review to determine if they meet the criteria for reporting to DOE in a noncompliance tracking system (NTS). The screenings are performed by compliance personnel that have undergone the training as required by Safety and Security DOE Regulatory Program (SSDRP) procedural requirements. The number of NTS reportable noncompliances identified during FY 2011 was:

- 17 worker safety and health reports, up 3 from FY 2010 
- 7 nuclear safety reports, down 5 from FY 2010

- 0 worker safety and health and nuclear safety criteria.

The DOE Office of Enforcement issued a Consent Order on January 7, 2011, (NCO-2010-04) for an unplanned radiation exposure in the INL Health Physics Instrumentation Laboratory (HPIL). The Consent Order contained four corrective actions that INL committed to complete to the satisfaction of DOE-ID. INL agreed to submit a monetary payment of $\$ 85,000$ and treat all segregated proceeding costs as unallowable. The DOE Office of Enforcement agreed to refrain from taking further enforcement action for any potential violations pertaining to the HPIL event.

The DOE Office of Enforcement issued a Preliminary Notice of Violation (PNOV) and Civil Penalty (CP) of $\$ 425,000$. The PNOV cited four violations of 10 CFR 824 Classified Information regulatory requirements. INL responded to the PNOV and CP on March 24, 2011, citing extenuating circumstances for DOE's consideration to further mitigate the amount of the CP. The DOE Office of Enforcement issued a Final Notice of Violation (FNOV) on April 18, 2011, stating that DOE finds no basis for modification of the PNOV and assessed a $\$ 425,000 \mathrm{CP}$, which required INL to treat all segregated proceeding costs as unallowable.

The DOE Office of Enforcement informed INL by a letter dated June 1, 2011, that they intended to conduct an onsite Regulatory Assistance Review of the classified information security program that supports the INL regulatory compliance program at the request of INL. The onsite review was conducted on August 8 to 11, 2011. The final report for that assist visit has not yet been received by INL.

The DOE Office of Enforcement informed INL by a letter dated August 1, 2011, that they intended to conduct an onsite investigation into the facts and circumstances associated with the June 1, 2011, inadvertent draining of the reactor vessel at ATR. The investigation was performed during the first week in October 2011.

\section{A-5.2 Environmental Regulatory Compliance}

The Environmental Management System (EMS) is the key INL system that helps ensure continued environmental protection and maintenance. The EMS supports the INL science and engineering mission with cost-effective, innovative, and user-friendly guidance for compliance with environmental requirements, addressing legacy and emerging environmental issues, enabling meaningful environmental stewardship initiatives, and monitoring environmental performance. INL's EMS follows the ISMS core functions from defining the scope of work and identifying the hazards through our regulatory review process, developing and implementing hazard controls through our procedures and through involvement by knowledgeable staff in the review of work control documents. The EMS staff also monitors work being performed to ensure that it is performed within the limits of the identified hazard controls, and to obtain feedback on the effectiveness of the controls to identify opportunities for improvement.

The FY 2011 performance of the EMS is measured by reportable environmental releases, notices of violation (NOVs), and office materials recycled.

No reportable environmental releases occurred during FY 2011. The Idaho Department of Environmental Quality (DEQ) alleged 17 violations related to the management of underground storage tanks during an external regulatory inspection in FY 2011. The majority of the alleged violations related to DEQ not accepting documents prepared by a previous contractor related to corrosion protection for tanks and lines. BEA is continuing to work with DEQ to resolve the issue. DEQ will issue a formal Warning Letter without an NOV or fines. INL's recycling initiative continued to grow through FY 2011, which includes co-mingled recycling and paper shredding. 


\section{A-5.3 Radiation Control Compliance}

In FY 2011 the number of radiological noncompliance events increased from FY 2010.

It was discovered at MFC, the first week of January 2011, at the HFEF Manipulator Repair Area, that two hot cell manipulator repair group workers had potentially exceeded their annual extremities Administrative Control Limit for radiation dose for calendar year (CY) 2010.

The suspension of all work on January 7, 2011, requiring an RWP at MFC and INTEC was implemented by MFC senior management due to broad problems in execution and planning of radiological work at that complex and then on January 21, 2011, a second suspension was initiated for radiological work. The curtailment was called to develop and implement a more in-depth approach for work process reviews and associated corrective actions.

The recent events at MFC that triggered the work suspension had included the Fuel Manufacturing Facility (FMF) glovebox (September 2010), the casting glovebox in the Analytical Laboratory (December 2010), and an unexpected high extremity exposure in the Hot Fuels Examination Facility (HFEF) (January 2011).

An INL-wide team was assembled and developed a recovery plan (PLN-3763, MFC Recovery Plan) to reestablish radiological work at MFC through the establishment of tailored, consistent, sustainable, and integrated work control and radiological control programs that facilitate the execution of research, operations, and maintenance work in a safe and compliant manner.

On January 4, 2011, the new INL ES\&H Director arrived and assumed responsibility for the ES\&H organization. The Radiological Control Director and several of the department's senior managers were replaced or reassigned. By the end of the quarter, a new Radiological Control Director had been appointed. The management change process is still continuing.

A consent order (NCO-2010-04) was signed on January 13, 2011, by BEA for the Health Physics Instrumentation Laboratory (HPIL) Unplanned Exposure Event that occurred March 22, 2010. The agreed upon amount by DOE and BEA to be paid for the violation is $\$ 85,000$.

The shutdown of radiological work at MFC in January 2011 due to noncompliances and work control issues resulted in several actions taking place, including a review of the MFC RWPs, the establishment of RWP review boards, management re-alignment, and re-enforcement of management's expectations. Plans (PLN-3763, MFC Recovery Plan, and PLN-3762, INL Work Control Corrective Action Plan) have been approved, PLN-3763 has been completed and PLN-3762 is being followed.

The Office of Health, Safety and Security Office of Enforcement and Oversight (DOE-HSS) completed a review of the Occupational Radiation Protection Program as implemented and recently enhanced at the INL. The assessment team found the BEA Radiological Protection Program to be compliant with the key provisions of 10 CFR 835. The HSS team noted that BEA has a very aggressive radiation protection improvement plan. If resolutions and improvements continue at the pace BEA has currently planned, the efforts should prove effective.

DOE-ID completed an "Assessment of the Effectiveness of Improvements and Corrective Actions for Battelle Energy Alliance Work Control and Radiation Protection Programs on PLN-3762 and PLN-3763" in September 2011 evaluating the timeliness, adequacy, and effectiveness of the improvement and corrective actions in the following areas: radiation protection, work control, and organizational effectiveness, and contractor assurance. The assessment determined that significant progress has been made; however, much more work remains to ensure that programs are implemented consistently. The assessment determined that corrective actions have been only partially effective due to the number of 
corrective actions still not completed and seven issues, three observations, and three recommendations identified from the assessment.

An HFEF radiation worker received an unexpected high dose of 3,580 mrem extremity dose in August 2011 while processing metallurgical samples. Key issues identified from the event are: (a) failure of the radiological control personnel to react appropriately to high beta dose rates; (b) inadequate RWP for sample processing work in the HRA at the facility; (c) inadequate procedure for sampling processing work in the HRA at the facility; and (d) inadequate management oversight.

The summary timeline above supports the conclusions from both the internal corrective action effectiveness review and the DOE-HSS conclusions of PLN-3762. Significant progress has been made; however, much more work remains to ensure that programs are implemented consistently. The assessments determined that corrective actions have been only partially effective due to the number of corrective actions still not completed. It will take some time for BEA to benefit with results from planned actions and corrective actions that have already been fully implemented.

\section{A-5.4 Injury Performance}

The TRCR for FY 2011 is 0.96, an improvement of almost 30\% compared to the FY 2010 rate of 1.37, indicating a recovery from that spike in performance. The FY 2011 rate of 0.96 equals the previous best year of performance in FY 2009, and is over 19\% better than the FY 2004 baseline rate of 1.19. Of the 19 major organizations comprising the Laboratory, 10 completed FY 2011 without incurring an OSHA recordable injury or illness. Additionally, in early July, employees at the entire ATR Complex completed 1 full year without incurring an OSHA recordable injury or illness.

The DART case rate for FY 2011 is 0.50 , an improvement of over $32 \%$ compared to the FY 2010 rate of 0.74 , also indicating a recovery from that spike in performance. The FY 2011 rate of 0.50 is also over $18 \%$ better than the FY 2004 baseline rate of 0.61 . Of the 19 major organizations comprising the Laboratory, 13 completed FY 2011 without incurring a DART case.

A majority of the occupational injuries and illnesses resulted from situational awareness, rather than systemic problems, as well as physical body failures. While this year's injury/illness rates represent one of INL's best years, we must break past this point for demonstrable progress. The causes of injury and illness cases, the challenges they create, and the fact that unique mitigations are the key to preventing injury and illness are well understood. A focus on heightened staff attention and awareness, employee safety team involvement to reduce injuries, and a Fitness for Duty initiative designed to ensure employees are physically capable and ready to perform their job tasks safely are improving our performance. An increased emphasis on communicating with employees and taking actions to reinvigorate the management observation process are producing results. Managers have been challenged to increase their presence at worksites and increase safety-related interactions with employees. We are also maturing in our proactive use of safety leadership, organizational learning, and engagement data from ES\&H and Gallup surveys. This data are being used as a predictive tool, focusing on organizations with poor performance and paying close attention to areas of concern.

Figure A-4 shows a graphical representation of historical TRCR and DART case rates. 


\section{Safety - How are we doing?}

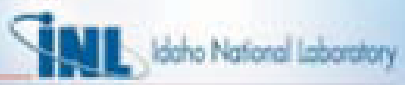

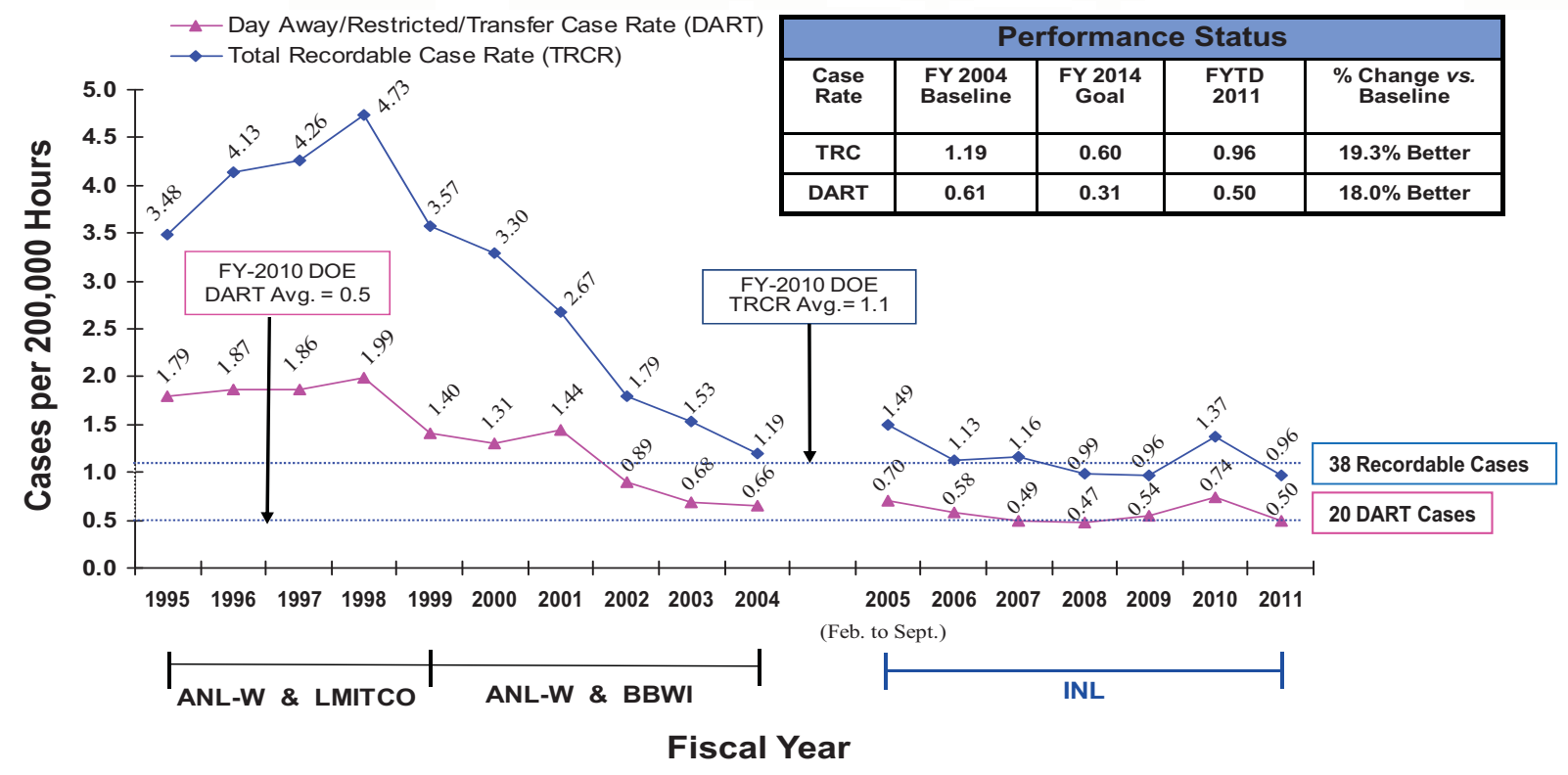

Data current through October 3, 2011

Figure A-4. Historical performance.

\section{A-5.5 Quality Assurance}

The Quality Management System (QMS) provides the strategic functionality to assure the Quality Assurance Program (QAP) enables the INL mission in the production of high quality products, services, and solutions using a variety of cost-effective, innovative, and technical processes for the performance and assessment of work. The QMS is influenced, designed, and implemented from National Consensus Standards, DOE requirements, and internal organizational policies and procedures formulated to mitigate risks associated with particular mission objectives. The QMS commitment to provide each customer with the highest quality deliverable in support of their desired performance results and outcomes applies to all INL activities including research, design, development, demonstration, manufacture, test, examination, and operational acceptance.

The QAP serves as the foundational basis for most Laboratory processes and other management systems, including the ISMS, and promotes the achievement of quality by collaboration with internal stakeholders through

- Planning and documenting requirements for items, processes, and services

- Incorporating the five core functions of safety into the QAP and all quality assurance (QA) work practices to continue the cycle of conducting work in a safe manner

- Controlling activities affecting the quality of those items, processes, and services

- Assessing program elements to verify compliance and recommend improvement

- Verifying the achievement of required quality 
- Analyzing and correcting conditions adverse to quality in a continuing process of self-improvement.

PLN-13000, "Quality Assurance FY-11 Management Plan," was revised during FY 2011 to better communicate the overall description of the business aspects and the major performance objectives for achieving the QA organizational vision.

The QA organization has been realigned with Performance Assurance to bring together complementary functions that support accomplishment of INL missions. QA models a customer-centered service organization providing education and expertise on quality assurance requirements as well as the tools for process improvement across the INL.

\section{A-5.6 Nuclear Safety}

Nuclear Safety Engineering (NSE) implements all aspects of ISM guiding principles and core functions by collaborating with stakeholders to effectively and efficiently integrate facility safety requirements into all aspects of work in, near, or interfacing with a nuclear facility. NSE has a robust program where work is well-defined and followed. Efforts to improve processes to meet the nuclear safety requirements are consistently pursued through collaboration efforts with stakeholders and NSE staff as well as assurance activities assessing NSE's ability to meet requirements and that of line organizations' ability to meet nuclear safety requirements.

Multiple assurance activities occurred for the year, including two significant reviews of the unreviewed safety question (USQ) process and the Criticality Safety Program. Minor issues, particularly the USQ process having administrative errors, were found in both assessments and opportunities for improvement that were identified were pursued.

The ISMS core function, Provide Feedback and Continuous Improvement, continues to be at the forefront of efforts of the NSE organization. Actions for continuous improvement in FY 2011 were:

- Previous feedback from the USQ assessment conducted in 2010 resulted in LWP-18001, "INL Unreviewed Safety Questions," Revision 3, which was implemented in February to include a review for controlled unclassified information, an update to several definitions, as well as improving guidance for completing the seven questions, and other minor changes. NSE continues to find opportunities for improving the process.

- The INL USQ process users requested NSE to initiate an effort to automate the USQ process. If funding permits, rollout of the new system is expected in 2012. Automation will not only make the process more timely, but will provide improvements in quality as comments from approvers can be sent back via automated emails from the system to disseminate needed changes. Other controls will be in place to prevent deficiencies found in the annual USQ assessment in 2011.

- NSE benchmarked the USQ processes of CH2M-WG Idaho LLC and the Advanced Mixed Waste Treatment Project in FY 2011. Further, NSE performed leadership roles for the Energy Facility Contractors Group (EFCOG) Nuclear Safety Steering Committee and the USQ subgroup. Through such efforts, NSE focuses on lessons learned and complex-wide best practices.

- This past year, NSE partnered with maintenance, other organizations within Applied Engineering, and Nuclear Assurance to establish ongoing dialogue to address implementation needs and opportunities for feedback and improvement in nuclear safety processes.

- During BEA contract transition, it was identified that 13 nuclear facility safety bases at MFC were not in full compliance with the safe harbor provisions of the Nuclear Safety Rule, 10 CFR 830, Subpart B. This past year, NSE completed upgrades to all 13 Documented Safety Analyses. 
- NS-18104, "INL Guide to Safety Analysis Methodology," was updated to include lessons learned, best practices, customer feedback, and plutonium equivalent curies methodology.

- NS-18204, "Criticality Safety Officer Qualification Plan," was strengthened to improve Criticality Safety Officer knowledge of their facilities.

- Criticality Safety Engineers have been assigned to specific facilities that have had deficiencies needing Criticality Safety Engineer attention.

\section{A-5.7 Criticality Safety}

The purpose of the Criticality Safety Program is to ensure appropriate actions are taken to prevent and mitigate the consequences of a criticality accident. The requirements of the Criticality Safety Program are documented in Laboratory Requirements Document (LRD)-18001, "INL Criticality Safety Program Requirements Manual." LRD-18001 complies with the requirements of 10 CFR 830.204, applicable DOE Orders/Standards, and the American National Standards Institute/ANS-8-Series Standards.

A mature and effective criticality safety program requires the involvement of multiple organizations. These organizations include Criticality Safety, Emergency Management, Engineering, Fire Protection, Nuclear Operations, Safety Analysis, Safeguards and Security, and Training. Because of this multiorganizational involvement, the INL Criticality Safety Program relies on, and is part of the ISMS. The Laboratory ISM Program, which includes Criticality Safety, is documented in PDD-1004, "Integrated Safety Management System."

The Criticality Safety Engineering Department works with Nuclear Operations, Nuclear Safety Engineering, the scientific community and project management to set expectations, identify and prioritize tasks, and allocate resources for activities using fissionable materials at the INL. Criticality Safety Engineering works with Operations personnel to analyze the hazards and criticality safety evaluations are performed that develop controls for prevention and mitigation of a criticality accident. Criticality Safety Engineering assists line management in the implementation of criticality safety controls. The Criticality Safety Program establishes requirements for feedback and improvement through review and assessment of work performed to ascertain that procedures are being followed and that process conditions have not changed to affect the applicable Criticality Safety Engineers. Criticality safety issues are documented, tracked, and resolved per Laboratory procedures and processes to ensure continual improvement.

The Criticality Safety Program was effective in FY 2011 in implementing the ISM five core functions. Criticality Safety management worked closely with nuclear safety analysts, operations, scientists, and researchers to define the scope of work, analyze criticality hazards, develop, and implement criticality controls as evidenced through all activities involving fissionable material being performed in FY 2011 within established scope and controls. Feedback and continuous improvement was achieved and effective through the performance of Criticality Safety Program required assessments and inspections identifying numerous issues. Improvement opportunities were identified in several areas to include Software Quality Assurance, training, Criticality Control Areas implementation, and the Criticality Safety Officer program. A deficiency was identified at Nuclear Materials Inspection and Storage facility with the fuel storage administrative limit exceeded. All issues were documented in the INL issues management system and have been or are being resolved per Laboratory procedures. 


\section{A-6 CORE FUNCTION FIVE - FEEDBACK AND CONTINUOUS IMPROVEMENT}

Core function five, feedback and continuous improvement, is effectively implemented; however, opportunities for improvement exist. Feedback is gathered for analysis through various reporting systems and communication mechanisms to ensure continual improvement in processes and performance. This section describes the primary mechanisms used by the INL ISM to ensure effective feedback and improvement. These mechanisms also comprise the CAS required by DOE Order 226.1A.

\section{A-6.1 CAS}

CAS faces the challenge to promote the right balance of assurance activity that enables INL to find, understand, and correct deficiencies and improve performance, while ensuring organizations are not burdened with nonvalue-added activity. The principle of reasonable assurance recognizes that management controls must be both effective and efficient and applied in a manner commensurate with the risks and the mission and activities of the implementing organizations. It recognizes that the potential for deficiencies, errors, or events remains, but that upon discovery, management action will be undertaken promptly to address such shortfalls, omissions, or errors to minimize the impact of such events and to learn from those events in an attempt to drive improvement. Ensuring sustainment of CAS improvement actions, such as increased management engagement in the field, is critical to demonstrate effective execution of long-term solutions to CAPs.

\section{A-6.1.1 CAS Effectiveness}

CAS has seen improvements across INL in collaboration and ownership of the system and tools. This is especially evident in improvements in the planning and execution of risk-informed assurance activity, the establishment of a high-volume/low threshold issues management system, and INL leadership and engagement in ensuring the effectiveness of corrective actions. Notable examples include the successful rollout of a management observation program, broader establishment of CARBs, and formation of a cross-organizational team to promote improvements to the issues management program. INL has witnessed a dramatic increase in documented evidence of leadership engagement with staff in the field. Significant effort has been put into collectively designing these programs in a way that will provide INL-wide trending data related to the work control process execution and better enable targeted corrective actions and process improvements. Quarterly reporting of management observations and other assurance activity to the INL councils has resulted in broader and increased engagement in understanding the health of INL and is driving improvements in performance measurement. Cause analysis and critique activity in response to events is resulting in increased quality, rigor, and effective mentorship. This is recently evidenced in the depth and breadth of the recent Low Level ATR Reactor Vessel investigation. The increasing visibility and attention into the corrective action process by leadership is noteworthy and will be continuously reinforced.

\section{A-6.1.2 Event Investigation}

Laboratory Performance has a vision to be a valuable resource to those responsible for conducting or interfacing with the INL investigation processes and to provide sufficient instruction and guidance to fulfill their responsibilities with an overall vision of becoming a learning organization that will systematically evaluate issues and improve behaviors, procedures, and systems to optimize INL's performance.

Improvements with the Event Investigation and Cause Analysis programs continued throughout FY 2011 and, although the average days to complete investigations for Occurrence Reporting and 
Processing System (ORPS) events increased slightly (43.8 days last fiscal year to 44.7 days this fiscal year), the quality of investigation and cause analysis reports has improved due to changes made at the INL.

The INL has established and chartered CARBs for all in-town and Site facilities. The purpose of a CARB is to review investigation reports and to ensure that the actions planned are directed at the causes of the event and will help in preventing recurrence of problem. Although the additional review provided by the CARBs has increased the amount of time it takes to process an issue through to implementing an action plan, the reviews have proven beneficial in that they have helped create better resolution to issues, better investigation results, more effective corrective actions, and more open communications through the investigation and cause analyses processes. To assist these new CARB members and INL managers in general, INL piloted a training course on developing effective corrective actions. Positive feedback from the class has led to the creation of an INL course aimed at improving the quality of action plans.

In conjunction with the addition of several new CARBs, the INL increased the number of qualified cause analysts by $58 \%$ (from 12 to 19 ) and is actively working to qualify additional personnel. A larger pool of analysts provides management with the ability to assign cause analysis to an analyst outside their organization when conflicts of interest exist, when they may be perceived, or when independence is needed. Mentoring of newly trained cause analysts and peer reviews of cause analysis reports is being performed to help drive improvements in the process.

Laboratory Performance also initiated a Critique Process Improvement Team to modify the critique process so that they focus on discovery of the facts and not the causes. Any need for cause analysis will be performed by qualified cause analysts using information gathered during the critique.

An independent assessment (IAS112191, Cause Analysis Process and Results) was performed in September 2011 to ascertain the factors in the BEA Cause Analysis process and its implementation that affect the timeliness of completing Cause Analyses and the outcome of the analyses. The assessment did not document any findings but identified three strengths and five opportunities for improvement. The INL is committed to addressing each of the opportunities during fiscal year 2012 so that the process continues to improve.

\section{A-6.1.3 Identify and Prioritize Risks}

Over the past couple years the Laboratory has placed emphasis on maturing contractor assurance processes and utilizing resources based on risk prioritization. In 2009, an Independent Assessment was performed on risk identification across the Laboratory (IAS101273). As a follow-up assessment to this assessment, Performance Assurance conducted another independent assessment in FY 2011 (IAS 112094). The purpose of this independent assessment was to ascertain the effectiveness of risk management within BEA and the effectiveness of the risk register, other risk management tools, and processes in place to manage risk.

The result of this assessment was assigned a rating of "Marginally Effective." The Laboratory as a whole is improving and moving forward in the Risk Management area, but is still lacking in consistent use of standard tools. Ranking and grading of risk was being performed in a variety of methods ranging from risk meetings to tools to aid in weighting. A high level of attention is being given to risk in the organization. Managers are aware of their risks and are actively managing the mitigation. This was demonstrated by the use of the Assurance Portfolio tool, by most managers, to manage risk. There was very little mention of any risk management tool in contrast to the 2009 assessment. 


\section{A-6.1.4 Committee/Council Oversight of Key Operational Events and Issues}

The Operations Council provides senior management leadership and strategic direction for implementation of the ISM. The Operations Council is chartered to identify risks and understand issues, to make or recommend decisions to the INL Executive Council, and to provide direction to the operational elements of the INL to ensure that operational excellence in the facilities associated with the INL is maintained and is constantly improving. The Operations Council works with the Battelle Energy Alliance Operations Committee (BOC), which is responsible for corporate oversight of operational risks at INL. The oversight and engagement of the Operations Council provides additional defense in depth to ISM effectiveness. Some of the FY 2011 examples of the Operations Council and BOC involvement and oversight are listed in the following subsections.

\section{Example: INL Work Planning and Controls Corrective Action (PLN-3762, PLN-3763)}

The Operations Council initiated and provided oversight in the planning, preparation, and execution of PLN-3762 and PLN-3763 in order to establish and sustain a high level strengthened work control, radiological protection, organizational effectiveness, and performance improvement activities. Because of the broad scope of the corrective actions (e.g., comprehensive RWP reviews, Work Observation Program), significant effort was made by the Operations Council to

- Enhance the interfaces and level of collaboration between management, organizations, and management systems

- Monitor the progress and effectiveness of the CAP through system reviews and evaluations, Council briefings, and effectiveness assessments

- Status the BOC and INL Leadership Management Team on strategy, progress, results, and effectiveness.

\section{Example: Integrated Budget Priority List - Balanced Priorities}

The Operations Council as a part of its oversight responsibilities prioritized integrated budget priority list work scope and Indirect General Purpose Capital Equipment Program purchases against mission and ES\&H needs. In response to resource uncertainties and changing budget scenarios, significant effort was made to identify divestment opportunities in operations. The Operations Council directed an ad hoc committee to take a fresh and innovative look at opportunities to reduce cost, integrate duplicative processes, and prioritize divestment. The Operations Council balanced the findings and recommendations of the ad hoc committee against the nonnegotiable aspects of Laboratory mission, ES\&H, Quality, and Nuclear Safety.

\section{Example: Management System(s) Oversight}

Changes were made to the management systems under Operations Council purview to improve upon the ability of INL operations to define and manage work scope and perform work within the established controls. Approved changes included standing down both the Facility and Site Services (F\&SS) and the Nuclear management systems and dividing their associated functions between the Work management system, Real Property management system, Asset Protection management system, and the F\&SS organization. The Operations Council also increased the frequency in which it reviewed management system portfolios and quarterly reports and provided guidance and feedback to MSLs on improving risk analysis, mitigation strategies, performance measurements, and incorporating ISM core principles.

\section{Example: BOC Interaction}

The BOC is responsible for the corporate oversight of operational risks at INL. The BOC evaluated management system performance, key project performance, and responsiveness to previous operational 
events and enforcement actions during FY 2011. The BOC concluded that management is taking steps to improve operational processes and respond to individual events. However, the BOC also recommended that management invest in a comprehensive improvement initiative that addresses the broad conduct of operations and nuclear safety concerns, drives improvements in management systems, and strengthens the CAS program. The Operations Council outlined a Sustained Operational Improvement Initiative to address these recommendations and scheduled for implementation in FY 2012.

\section{Example: Senior Operations Working Group}

The DOE/BEA Senior Operations Working Group is designed to foster a culture where BEA line organizations routinely identify problems and actively seek gaps to excellent performance in daily operations. The working group provides both a mechanism for assuring alignment between BEA and DOE-ID, and a forum where BEA and DOE-ID management can discuss implementation issues and questions that arise. The Working Group continues to meet and discuss issues, barriers to success, recommendations, etc.

\section{Example: Operations Council Dashboard}

The Operations Council Dashboard was added in FY 2011 as a tool to report on operational assessment performance, incidents and events management, correctives action management, and management system performance. The Operations Council Dashboard periodically reviewed the DOE/BEA working group meetings. The DOE/BEA Senior Operations Working Group emphasized the importance of staying focused on those performance measurements and criteria identified in DOE O 226.1B.

\section{A-6.1.5 Occurrence Reporting and Lessons Learned}

Eighty-nine occurrences were reported into the ORPS during FY 2011. Nineteen fewer occurrences were reported in FY 2010. These 89 occurrences were reported from 13 facilities.

Table A-7 lists the number of occurrences by quarter and shows an elevated level during the first and second quarters. This was approximately a $25 \%$ increase in the number of occurrences from the previous year. This increase was primarily the result of an increase in the SigCat 4 events that increased by greater than $70 \%$ over the previous year. The reporting areas that had increases over the previous year are: Management Concerns/Issues, Documented Safety Analysis Inadequacies, Discovery of Suspect/Counterfeit and Defective Items, and Personnel Contamination.

Table A-8 lists the number of occurrences by ORPS Significance Category. Significance Categories (SigCat) 1-4 are based on impacts of the occurrence on safe facility operations, worker safety and health, or regulatory compliance. The two Operational Emergencies were reported for wildland fires.

Thirteen occurrences were nuclear safety basis issues and were categorized as moderate ( 5 positive USQs and 3 TSR violations), 2 were Actuation of Safety Class SSC, 2 were Contact with Hazardous Energy, and 1 was a management concern. 
Table A-7. Occurrences by fiscal year quarter.

\begin{tabular}{|c|c|}
\hline FY Quarter & Number \\
\hline 1 & 24 \\
\hline 2 & 25 \\
\hline 3 & 21 \\
\hline 4 & 19 \\
\hline Total & 89 \\
\hline
\end{tabular}

Table A-8. Occurrences by ORPS significant category.

\begin{tabular}{|c|c|}
\hline Significance Category & Number \\
\hline $\mathrm{OE}$ & 2 \\
\hline $\mathrm{R}$ & 1 \\
\hline 1 (significant) & 0 \\
\hline 2 (moderate) & 13 \\
\hline 3 (minor) & 37 \\
\hline 4 (some) & 36 \\
\hline Total & 89 \\
\hline
\end{tabular}

Two operational emergency events were reported for wildland fires and were outside INL control. The SigCat R report was submitted for issues associated with pre-job planning and in-field supervision and enforcement of procedural compliance. The corrective actions are for the most part completed for this recurring occurrence report with essentially three action types remaining - revise corrective action review board charters, monitor and report on line management engagement and work observations, and conduct an effectiveness assessment.

The most recent occurrence reporting quarterly performance analysis of occurrences and nonreportable events identified in the period of July 2010 through June 2011 did not identify any significant increasing trend besides identifying Suspect/Counterfeit Items (fasteners), which is primarily driven by increased surveillance.

Figure A-5 provides the quarterly number of occurrence reports by quarter for the last 2 years broken out by SigCat 2 (and above), SigCat 3, and SigCat 4. As indicated previously, a considerable increase in the number of SigCat 4 occurrences has happened, but not in the more significant events.

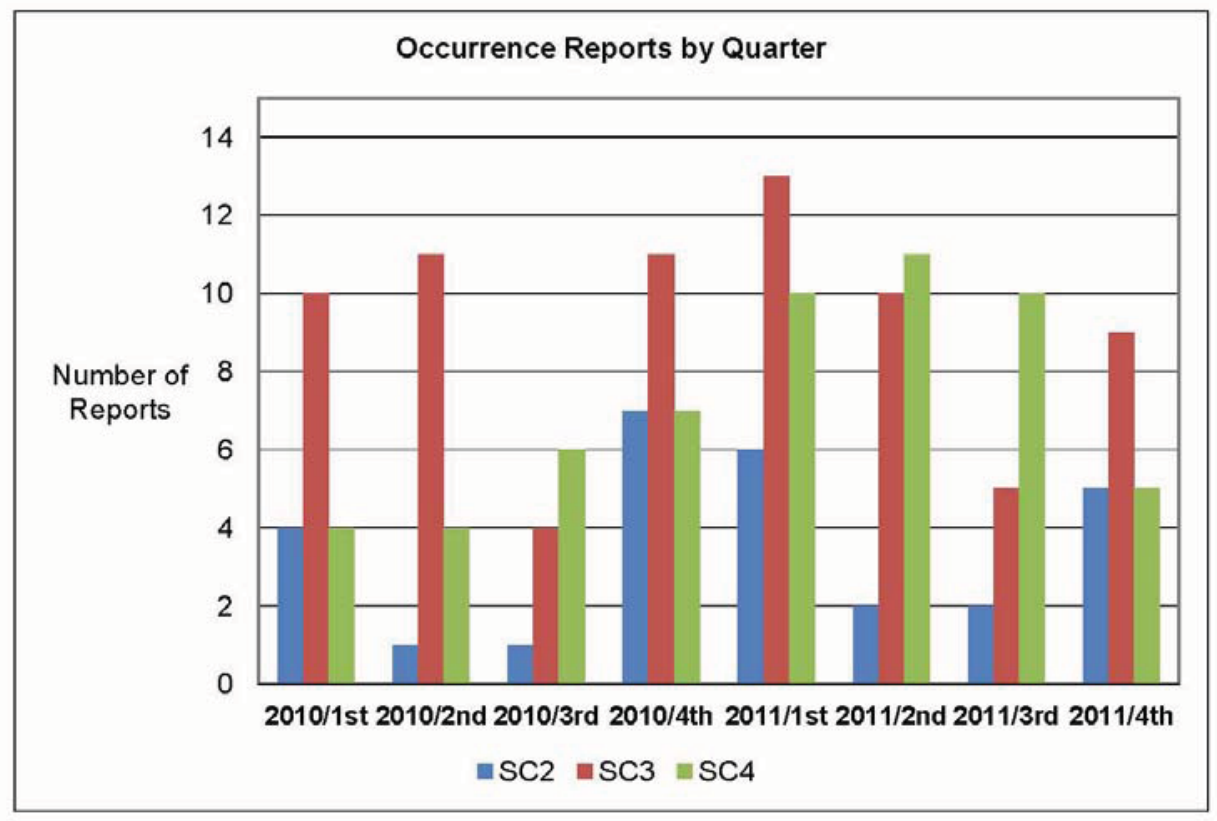

Figure A-5. Quarterly number of occurrence reports by quarter for the last 2 years. 
INL procedure LWP-13850, "Processing Lessons Learned and Operating Experience Information," provides the instructions and responsibilities for implementing specific elements of the lessons learned system description in PDD-171, "INL's Contractor Assurance Management System Description." The lessons learned system is an integral part of the feedback and improvement processes required by DEAR 48 CFR 970.5223.1, Integration of Environment, Safety, and Health into Work Planning and Execution, and described in PDD-1004, "Integrated Safety Management System." LWP-13850 implements the lessons learned requirements of DOE O 210.2, DOE Corporate Operating Experience Program.

The INL's goal for INL Lessons Learned Program (LLP) is to effectively and efficiently use lessons learned from the DOE LLP, industry, and INL operating experience to improve INL efficiency and safety. Learning and applying the lessons from operating experience is an integral part of the INL culture and is encouraged by managers throughout the organization. INL personnel regard operating experience as helpful and important to them, and they use this information at every opportunity. Methods of using operating experience are structured to provide applicable information to the right personnel in time to make a difference. The timely use of operating experience better prepares workers for their jobs, helps develop innovative contingency plans, and, most importantly, prevents events. Additionally, when INL personnel analyze the causes of significant events, operating experience is routinely reviewed to determine if and why previous lessons were not effectively learned.

Activities conducted in this reporting period to move the INL toward this goal included two assessments IAS111949, Benchmarking Pacific Northwest National Laboratory Lessons Learned Program, and IAS11570, Effectiveness of Lessons Learned Program Implementation, which included an INL survey to determine the level of awareness of the LLP.

The benchmarking assessment identified several opportunities for improvement of the INL LLP that fall in three general categories: process changes, software changes, and staffing changes. The April 2011 INL LLP survey identified the following key thoughts that indicate a need for improvement: (a) approximately half of the survey participants either do not use of do not know about the LLP, which indicates a need to increase INL LLP awareness, (b) most of the respondents who had participated in a noteworthy activity indicated they did not submit a lessons learned, and (c) a need to improve understanding relevance of lessons learned to others across the INL.

The assessment on the effectiveness of the lessons learned program identified five recommendations for improvement of the program: (1) trending program metrics; (2) improving the LLP access from the Nucleus web page, which was previously completed; (3) Summarizing the lessons learned to assist reviewers of the specific INL applicability; (4) improving program visibility; and (5) consider adding a full time LLP subject matter expert (SME) to the Laboratory Performance organization.

An undercurrent that is apparent in the survey results is a general lack of management support for LLP use. A common characteristic of organizations that use Operating Experience/lessons learned effectively is strong line management support to instill an attitude that lessons learned adds significant value to operations and work activities.

The Opportunities for Improvement identified in these program evaluation activities are being tracked in ICAMS and will be implemented when fully analyzed, prioritized and funding identified to improve the program.

The use of the INL lessons learned system to communicate lessons based on events has more than tripled in the last couple of years. In addition, reviews are improving in timeliness with a couple of notable exceptions; however, recent changes in personnel should improve this performance. 


\section{A-6.2 Major Continuous Improvement Actions}

\section{A-6.2.1 Continuous Third Party Verifications}

\section{ISO 14001:2004 Audit}

The EMS at INL, BEA, is recommended for recertification to ISO 14001-2004 with no nonconformities. The EMS shows evidence of positive practices in numerous areas including:

- Continual improvement evident in Recycling Program:

- Commingled collection

- Informative signs on containers

- Employee training includes interesting "drag and drop" test

- Diversion rate exceeded target by $3.9 \%$.

- Performance Feedback process Improvements:

- Added Management Observation process with Scantron tool

- Measured improved quality of the Causal Analysis process

- Produced a "Trending Analysis Guide" to better use data from feedback process.

- Sustainability program improvements:

- Twelve noteworthy improvements ranging from assessing $90 \%$ of the buildings eligible for Guiding Principle certification to securing Strategic Investment Funding for 4 years worth of sustainability projects.

- Excellent means used for internal communication.

- Excellent deployment of signs and posters

- Have included focus groups on use of iNotes

- Recent "INL Team Talk" issue promotes awareness of the ISO 14001 recertification audit and saving to be made by duplex printing.

- Senior Management Team members interviewed have clear knowledge of how EMS works to prevent impacts. Examples include:

- Preventing inappropriate radiological work

- Recognized role of individuals in system

- Interest in leading more sustainable landscaping at site where appropriate.

- Proposal Risk Evaluation and Preparation System and Hazard and Risk Planning System simplified, improved, and more user friendly.

- Training system strengths:

- Excellent process of aligning requirements, work processes, training needs and training content

- Feedback provided to content owners and stakeholders in training outcome

- Good focus: Training to the process rather than requirements

- Training department provides good support to ES\&H and other SMEs

- Posted training metrics at ATR showed attention to continual improvement

- Electronic Change Request process upgraded using input from users.

- Memo from ES\&H Director simplifies 2012 EMS Objectives and Targets.

- Improved efficiencies noted in Environmental Checklist process: 
- Consolidated "sources of impacts" from more than 20 to 6 by grouping like items together

- GDE-8100 reduced in complexity; 10 fewer pages.

- Laboratory Performance has improved link between Independent Assessment System (IAS), ICAMS, and EDMS using ICAMS issue numbers, status reports, and case files.

- SMC Heating Plant improvements reduced fuel consumption as measured by gallons per Heating Degree Day.

- Employees interviewed at ATR showed good knowledge of the work planning process and environmental requirements of their jobs.

- Plans to connect ATR complex to commercial power will reduce diesel fuel use by generators.

- Integrated Transportation and Fleet Services continues to improve energy performance, winning green fleet and sustainability awards in 2011.

- At MFC, good working relationships between Plant Services and facility users.

- The active role taken by Project Integrator and Building Supervisors helps communication

- Production Support at MFC working to identify "Green Space" on schedules to document windows free of maintenance shutdowns

- Fuels and Applied Science Building team showed excellent knowledge of procedures, operational controls and monitoring requirements and recordkeeping.

\section{Federal Electronics Challenge}

DOE-ID and the INL received a bronze Federal Electronics Challenge award for their 2010 activities. The award was presented at a ceremony in Washington, D.C., in September 2011.

The 2011 activities are completed for the 2012 Federal Electronics Challenge silver award application. New activities that were completed for 2011 include a PrintSmart campaign and survey, and conversion of all computers and monitors to Energy Star power management features. The INL reset all monitors to enter "sleep" mode after 20 minutes and computers after 60 minutes to comply with Energy Star settings.

\section{A-6.2.2 Safety Leadership Strategy}

Safety performance began to improve in July of 2010, which coincided with the kick off the strategy with Rocky Bleier and workshops held with frontline workers as an action from CAP 3762. Emphasis continued into 2011 with the kickoff of a "safety breakthrough" theme and focus areas on multiple fronts. Specifically, Gallup engagement actions continue, management observations has increased presence in the field and better dialogue with staff, improved recognition through Laboratory Health Community of Practice actions, Caring 24/7 actions such as Fitness For Duty standards and Wellness physical assessments to all employees, automated external defibrillators (AEDs) installed in town facilities' and additional fitness centers established at key locations. These actions target greater situational awareness. Additional actions geared specifically to management include providing training on ES\&H with a focus on ISMS principles and practical applications. Each LMT member was given an ES\&H score card. Included in their briefing package was a status of their organizations ES\&H training, injuries fiscal year to date (FYTD) as well as contract to date, information regarding sustainability goals, status of ergonomic software compliance by staff, a summary of Gallup key questions sorted by managers within their organization, and a summary of the safety culture survey data for their organization as compared to the company average. Each LMT met with ES\&H senior management to review their organization specific data and discussed opportunities for improvement. The survey data in particular have been viewed as predictive data. As the above actions mature, cumulatively they will have an effect on situational awareness and long term improved safety culture and performance. 


\section{A-6.3 Status of Opportunities for Improvement Identified in the FY 2010 ISMS Annual Effectiveness Review}

Specific opportunities and ongoing improvement activities from the FY 2010 effectiveness review "INL/EXT-10-20387 IAS11457" are discussed in the following subsections.

\section{A-6.3.1 Adequacy of Controls for "Skill of the Craft" Activities}

During its first triennial VPP recertification in 2009, the Office of Health, Safety and Security (HSS) DOE-VPP Team performed a review from October 19 to 30, 2009, in which they concluded that no hazard analysis is documented if the determination in the scope of work falls under "routine activity envelope" or "skill of craft". The hazards and risks are considered low and the performer is considered to have sufficient training and knowledge to perform the work safely. The HSS team noted several examples where additional controls from a documented hazards analysis might have improved the performance and execution of low hazard high frequency work activities. The HSS team recognized the reliance INL places on worker skill and awareness for routine, low-risk work and suggested that INL should revise its work control processes to ensure hazard analysis is documented for all work and that definition as routine activity or skill of the performer is based on the documented hazard analysis.

This concern was also pointed out in the FY 2010 ISMS Effectiveness Review. The following actions have taken place or are in progress as a result of the 2010 ISMS Effectiveness Review:

- LWP-21220, "Works Management," was revised as stated in the ICAMs response to relocate decision step for the determination of Routine Activity Envelope applicability until after initial hazards analysis has been completed. The revision of LWP-21220 also converted the procedure from an electronically delivered process to a flat file and is in the final stages of review.

- An evaluation was performed on the use of the OSHA 3071, 2002 (revised) to analyze routine hazards. LWP-21220, was designed to align with and execute the 5 core function of Integrated Safety Management System. As such, LWP-21220 is consistent with the OSHA Job Hazard Analysis (JHA) process for analyzing 'routine' hazards.

- Several organizations have developed Laboratory Instructions to cover routine hazards (e.g., F\&SS Machine Shop, Transportation Maintenance Shop "Big Shop," and Nuclear Maintenance). Additional Laboratory Instructions addressing routine hazards will be developed as the need is identified. INL launched a Sustained Operational Improvement Initiative in late FY 2011 which includes actions to enhance LWP-6200, "Maintenance Integrated Work Control Process." These enhancements include revisions to the planning level screening criteria (tool pouch, minor maintenance, planned work) to provide better consistency in the screening process, attendant review of the "Skill of the Craft" checklists to ensure that CCR can be demonstrated for routine hazard mitigation, and development of laboratory instruction for routine hazards that are not addressed by skill of the craft. Additional training will be provided to individuals that perform work screening activities using a blended delivery method (dynamic learning activities) to ensure routine hazards are appropriately addressed.

Previous internal and external assessments, including this annual ISMS review identified that work planning and lack of documented hazards analysis associated with skill of craft and routine activity envelope has not been sufficient to ensure safe and successful operations. Corrective actions have been formulated to address the perceived shortcomings but have been ineffective as evidenced by continued events associated with work planning and execution for skill of the craft and routine activity envelope activities.

When hazards are not identified, analyzed, mitigated, and communicated to the worker, the worker becomes the last line of defense. Documented evidence that this dialogue has taken place for skill of the 
craft and routine activities establishes defined boundaries and alleviates unnecessary vulnerabilities to the INL.

\section{A-6.3.2 Hazard Identification and Control Opportunity for Improvement from FY 2010}

See also Sections 1.5 and 4.1

The opportunity for improvement identified in the FY 2010 annual ISMS effectiveness review was: "In response to the hazard identification and control process assessment, IAS101410, [March 2010] INL is verifying the effectiveness of individual corrective actions to determine if the actions addressed the issues and recommendations are still being implemented and are effective for minimizing future events."

In May 2010, INL developed a Corrective Action Plan (CAP) (PLN-3492, "Corrective Action Plan for the INL Hazard Identification and Control Processes") to address the issues identified in the management assessment IAS101410, "INL Hazard Identification and Control Processes." However, implementation of IAS101410 action items in PLN-3492 was later deemed to be ineffective by the assessment report, IAS111813, "Effectiveness Review for Facility and Site Services Corrective Actions from PLN-3492." As a result of this and to address nine BEA common cause analyses, DOE reviews and Consent Orders, and events involving radiological work spanning the past 2 years, INL wrote PLN-3762, "INL Work Control Corrective Action Plan." The corrective actions in PLN-3762 are underway, and as discussed in sections 1.5 and A-4.1, are having the intended effect.

\section{A-6.3.3 Radiation Control Opportunity for Improvement from FY 2010}

The opportunity for improvement (OFI) identified in the FY 2010 annual ISMS effectiveness review was: "INL is currently conducting a follow-up common cause analysis on the radiological control noncompliances and the results will determine the path forward."

A formal cause analysis was performed in July of 2009 on 11 radiological control events occurring from March 15, 2009, to May 18, 2009, and a CAP [PLN-3492] was developed. An effectiveness assessment of the CAP was completed in July 2010 and found that implementation of the corrective actions was ineffective. A common cause analysis team was chartered by BEA's Operations Council on November 17, 2010, to analyze an additional 27 events that occurred from May 19, 2009, to November 12, 2010. The Common Cause Analysis, INL/MIS-10-20735, was completed December 17, 2010. The common cause analysis identified similarities and differences between the first and second cause analyses in an attempt to evaluate previous corrective actions and as an aid in determining additional actions to be taken in PLN-3762. The corrective actions for these OFIs are currently in process and tied to PLN-3762, which is discussed in detail in sections 1.5 and A-4.1.

\section{A-6.3.4 Contractor Assurance OFIs}

The CAS OFIs are (a) An opportunity to improve organizational understanding of required assurance implementation activities; (b) An opportunity to even better link risk mitigation with assurance; (c) An opportunity to improve the timeliness of identification and documentation of issues, potential weaknesses, or conditions needing management attention and ensuring entry into the Issues Management process from all types of assurance activities; and (d) In general, an opportunity to improve timeliness of Lessons Learned reviews and usage of the Lessons Learned database (see section A-6.1.2).

\section{CAS OFI \#1 from FY 2010}

An opportunity exists to improve organizational understanding of required assurance implementation activities. Actions taken: 
1. Provided reinforcement communications to $80 \%$ of applicable Assurance Coordinators reminding them to include appropriate risk-based required assurance activity in the assurance schedules.

2. Communicated and reinforced required assurance activity expectations to management based on assessment results associated with their directorate. This was accomplished through meeting with each directorate to provide feedback on CAS performance.

\section{CAS OFI \#2 from FY 2010}

An opportunity exists to even better link risk mitigation with assurance. Actions taken:

1. Interviews held with management system leads and INL Management System SME to provide feedback and two-way communication regarding their portfolio risks. This was done through a combined assessment with ISMS MSL.

2. Updated template for reporting quarterly assurance portfolios (TEM-13732) based on assessment results and review feedback.

3. Ongoing assurance portfolio reporting (quarterly) at the Councils. Risks/key issues are discussed with each portfolio presentation.

4. Established a required risk-ranking field in the assurance scheduling database to drive toward association of each assurance activity with a corresponding risk.

\section{CAS OFI \#3 from FY 2010}

An opportunity exists to improve the timeliness of identification and documentation of issues, potential weaknesses, or conditions needing management attention and ensuring entry into the Issues Management process from all types of assurance activities. Actions taken:

1. Performed assurance activity to document level of compliance with entering issues into ICAMS found during assessments. This was accomplished in FY 2011 through meeting with each directorate to provide feedback on CAS performance.

2. Established two additional CARBS to cover all geographic areas of INL to evaluate and mentor and reinforce expectations regarding effective corrective actions from assurance activities and cause analysis.

\section{CAS OFI \#4 from FY 2010}

In general, an opportunity exists to improve timeliness of lessons learned reviews and usage of the LLP database. Actions taken:

1. Performed an assessment of organizations use of the LLP database and lessons learned reviews. This was accomplished in FY 2011 through meeting with each directorate to provide feedback on CAS performance.

2. Benchmarking performed with Pacific Northwest National Laboratory to drive toward improvements in the tools and process. Actions underway include establishment of a new "quick share" feature in the LLP database.

\section{CAS OFI \#5 from FY 2010}

Opportunities for improvement in FY 2011 exist for strengthening metrics and the use of ICAMS data in reporting. Actions taken:

1. Formed a cross-organizational team to promote improvements to the issues management program. 
2. Produced a recommended revision to bins that align to management system structures and submitted to MSLs for consideration of FY 2012 implementation.

3. Piloted and implemented classroom ICAMS training (OINL 1532).

4. Established a trending guide for ICAMS (GDE-574).

5. Established a guide for ICAMS usage (GDE-562).

\section{A-6.3.5 BOC Concern that Safety Leadership Strategy Continue}

Safety performance related to situational awareness was a concern raised by the BEA Operations Committee in 2010. A peak in the 6-year BEA performance period for both TRC and DART occurred in FY 2010. However, in 2011, safety performance rebounded back to one of the best years under the BEA contract. Five of the last 6 years have demonstrated better performance than any previous contractor. Contributors to this rebound can be attributed to multiple factors, which include the Safety Leadership Strategy. Safety performance began to improve in July 2010, which coincided with the kick off the strategy with Rocky Bleier and workshops held with frontline workers as an action from CAP 3762. Emphasis continued into 2011 with the kickoff of a "safety breakthrough" theme and focus areas on multiple fronts. Specifically, Gallup engagement actions continue, management observations have increased presence in the field and better dialogue with staff, improved recognition through Laboratory Health Community of Practice actions, Caring 24/7 actions such as Fitness For Duty standards and Wellness physical assessments to all employees, AEDs installed in town facilities' and additional fitness centers established at key locations. These actions target greater situational awareness. Additional actions geared specifically to management include providing training on ES\&H with a focus on ISMS principles and practical applications. Each LMT member was given an ES\&H score card. Included in their briefing package was a status of their organizations ES\&H training, injuries FYTD as well as contract to date, information regarding sustainability goals, status of ergonomic software compliance by staff and a summary of Gallup key questions sorted by managers within their organization and a summary of the safety culture survey data for their organization as compared to the company average. Each LMT met with ES\&H Sr. Management to review their organization specific data and discussed opportunities for improvement. The survey data in particular has been viewed as predictive data. Gallup data related to the safety leadership question has improved from 4.02 in 2009 to 4.20 in 2011. Cumulatively, as the above actions mature they will have an effect on situational awareness and long term improved safety culture and performance.

\section{A-6.3.6 Line Management in Shared Facilities}

The OFI identified in the FY 2010 annual ISMS effectiveness review was: "Opportunities for improvement are being evaluated that relate to ensuring full understanding of line management, roles and responsibilities, and operations authorization when work space is shared between different organizations and management systems. IO-008547.”

IO-008547: "Confusion on line management is not consistent with ISMS and clarity is needed in LWP-9500, "Laboratory Excellence Program Organization and Administration." In particular, a horizontal work control process is attempted to be connected to a vertical line management structure, which further complicates and confuses the matter."

Proposed actions are to determine what changes are required to LWP-9500 and to revise LWP-9500, accordingly. The due date for the corrective action is November 30, 2011.

\section{A-6.3.7 Training OFI}

The OFI identified in the FY 2010 annual ISMS effectiveness review was: "INL will evaluate results of a current training assessment for improvement opportunities." 
The INL Executive Council chartered the Independent Oversight group of the Laboratory Performance directorate to assess the effectiveness of training provided to INL employees. The specific objectives of this assessment (IAS101360, "Independent Assessment of the INL Training Program") included the following: review and evaluate the INL structures, programs, and processes that provide employees with the training necessary to establish and maintain CCR; determine if the Laboratory provides the appropriate amount and depth of training to employees to both comply with applicable laws and regulations and ensure that employees perform their jobs safely and effectively. Additional focal areas also included evaluating the effectiveness of training provided to new employees and subcontractors.

Lessons learned about training at the INL included:

- Inconsistent training quality - some ineffective, some pockets of excellence

- No consistently adhered-to set of training standards and expectations

- Training practices, processes, tools and outcomes vary widely

- No one group owns INL-wide training standards, tools, processes, and evaluates training effectiveness INL-wide

- Managers do not consistently develop and monitor their employees' training plans to ensure that competencies are CCR - nor do they have sufficient tools for this

- Training needs to be better targeted so we don't over or under-train our workforce; training is not always the answer for performance gaps

- INL can benefit from greater integration among training and development programs.

In response to the finding and opportunities for improvement identified in the report IAS101360, the following actions were taken:

- Consolidated INL Training Services organization within Human Resources and Diversity (improves training and development integration and focus)

- Deployed new management

- New organization is collaborating with training stakeholders to systematically:

- Establish and communicate clear training standards and expectations

- Provide practices, tools, processes to meet standards (graded approach) - and hold SME trainers accountable for adherence

- Focus on improved analysis of training needs and evaluation of training effectiveness - it's all about performance

- $\quad$ Provide processes and tools to assist managers in developing annual training plans and monitoring them to ensure CCR

- Collect and share training best practices and lessons learned

- Use self-assessments and independent assessments to evaluate adherence to training standards, and identify barriers and improvement opportunities. 


\section{A-7 EIGHT GUIDING PRINCIPLES OVERVIEW}

PDD-1004 describes how INL follows the ISM eight guiding principles in establishing and performing the ISM five core functions to integrate safety into management and work practices to ensure public, worker, and environmental protection during mission accomplishment. The following sections provide a brief overview of the process.

\section{A-7.1 Guiding Principle One - Line Management Responsible for Safety}

Guiding Principle one, Line management responsibility for safety, is effectively implemented. As described in detail in PDD-1004, line management at the institutional, facility, or individual activity level, ensures hazardous work is planned, analyzed, controlled, and authorized by line managers. These managers understand the technical basis and associated hazards of the work, are aware of all activities, knowledgeable of institutional and facility safe operating requirements, and manage change control (Defense Nuclear Facilities Safety Board Technical Report 36). Line management is responsible for safety and assumes the direct responsibility to achieve the commitment to safety and protection of the environment through the active identification, evaluation, prevention, and mitigation of hazards.

This year enhancements occurred in the areas discussed below:

1. PLN-3762 actions - Management Observations; new leadership at MFC

2. Mandate to Manage, a 29-hour course, offered six times a year, delivered to managers to better understand operational business processes, was initiated this year. The ES\&H module includes elements of basic ISM roles and responsibilities for managers.

3. The Laboratory Director's office has required LMT members, once a month, to discuss the injuries occurring in their organization - the cause as well as actions taken to prevent similar situations. A new categorization of injuries was baselined in order to identify elements that are within INL control. (This is used only for LMT not for company-wide distribution).

Guiding Principle 1 implementation follows a robust, effective INL process that is closely related to Guiding Principles 2 and 7. Opportunities for improvement are being evaluated that relate to ensuring full understanding of line management, roles and responsibilities, and operations authorization when work space is shared between different organizations and management systems.

\section{A-7.2 Guiding Principle Two - Clear Roles and Responsibilities}

Guiding Principle two, clear roles and responsibilities, is effectively implemented and described in detail in PDD-1004. Work performance expectations for managers and employees are communicated in a variety of ways. Initially, contract requirements are translated into Laboratory-level documents and processes, with roles and responsibilities assigned to organizations, managers, and individual employees. General roles and responsibilities for INL management and employees are described in LWP-9500 and in employee position descriptions. Roles and responsibilities are further defined at the facility level.

Activity-level roles and responsibilities are even more prescriptive and are associated with specific jobs or activities. Controlled documents provide roles and responsibilities for safe performance of work at the Laboratory, facility, and activity levels.

A combined independent assessment [IAS11576, IAS11575, and IAS11875] was completed of Management Systems and Portfolios in FY 2011. The purposes of the combined assessment were to: independently evaluate the data in management system assurance portfolios reported to the Management Council for alignment with the council's needs and quality. The council must make good risk-based 
decisions; determine the degree of understanding and alignment between Management System's and the ISMS; and assess the alignment of quarterly reporting to assurance portfolios, including whether portfolios measure the effectiveness or "health" of the management systems functions and processes, which is the "next step" in the maturity of INL management systems. In response to the opportunities for improvement identified for ISMS in this assessment, the ISMS office is reinvigorating its engagement with the management system leads to help ensure that management system assessment activities reflect the major ISMS expectations (eight guiding principles, five core functions, requirements rolldown, training and qualifications, issues management, areas for improvement) for integrating safety into processes and functions, addressing the highest risk areas, and ensuring the effectiveness of corrective actions.

The newly introduced MOP (discussed in section 1.4 in more detail) has so far proven to be useful in reinforcing the ISMS guiding principles and core functions and in particular Guiding Principle 2, clear roles and responsibilities. A regular and purposeful management presence in the field has been developed with an intended outcome of reinforcing the understanding roles and responsibilities. The flexible approach to develop MOP plans has allowed the organizations to meet specific or unique needs of their workers and mission. The INL Independent Coaching Team was a valuable tool in mentoring and training managers. Current plans and strategies to maintain the MOP will help ensure its continual improvement and sustainment.

Specific actions have been taken to improve management systems, but INL will continue in FY 2012 to look for improvement opportunities related to Guiding Principle 2.

\section{A-7.3 Guiding Principle Three - Competence Commensurate with Responsibilities}

Guiding Principle three, CCR, is effectively implemented. People and their professional capabilities, experiences, and values are the Laboratory's most valuable asset. INL's process for ensuring an employee has competence CCR places a high priority on recruiting, selecting, and retaining staff that have an indepth understanding of both the safety and the technical aspects of their jobs. Training was stood up as its own management system in 2011 in response to the IAS101360 assessment. A major part of this effort was to strengthen CCR, see discussion in section A-6.3.7.

INL's diverse set of work activities dictates the need for a highly flexible and robust CCR process, which is described in detail in PDD-1004. The CCR requirements for processes such as work control are defined based on the risks, hazards, and complexity of the type of activity, facility, and worker. Management is responsible for understanding the specific ES\&H hazards and implementing the appropriate mitigation strategies in conjunction with the applicable regulatory drivers and process requirements.

\section{A-7.4 Guiding Principle Four - Balanced Priorities}

Guiding Principle four, balanced priorities, is effectively implemented. INL has continued efforts to integrate our business and budget process used to define Laboratory scope and work activities and balance safety, programmatic, and operations priorities. These processes, as described in detail in PDD-1004, translate Laboratory strategies into work scope and ensure that ES\&H, Quality, and Nuclear Safety requirements are met and resources are allocated to balance mission accomplishment with protection of the public, workers, and the environment. A well-defined scope of work, together with related resource cost and schedule elements is vital to the ISM for the following reasons:

- It sets the stage for the scope and depth of hazards identification analysis and work controls 
- Is the primary factor in establishing expectations and accountability

- Provides the foundation for budget formulation allocation process to identify and fund key ES\&H, Quality, and Nuclear Safety resources required to perform work safely.

Key improvements to INL's business and budgets process include:

- Significant modifications to key elements of the Work Planning Cycle and Project Management Enterprise, LWP-7390, "Project Management Process," used to flow down Laboratory requirements to work planning activities and ensure ES\&H, Quality, and Nuclear Safety review of budget/funding requests and planning documents. This included the:

- Consolidation, clarification, simplification, and tailoring of INL work scope management procedures and forms used for both projects and direct-funded work scope and for indirectfunded nonproject work scope. This resulted in the implementation of the INL Work Authorization and Documentation Form 415.19.

- Modification, alignment and automated required use of the Environmental, Safety and Health Radiological Control Budget Planning Checklist (Form 130.06) within the INL work authorization process. Form 130.06 is required prior to approval of the INL Work Authorization and Documentation and provides guidance, documents the hazards and risks associated with all INL work activities, and directs line management to consider ES\&H, Quality, and Nuclear Safety resources required to mitigate the risks and perform work safely. It is also required as a part of making baseline change requests.

- Making INL Governance Councils versus the financial management organization responsible for budget target evolution. Integrated priority lists were developed by organizations and reviewed and prioritized through the Councils. Final adjustments to the budgets were made the institution level through the Executive Council. The Councils are a key instrument to balancing priorities and effectively integrate ISM across the Laboratory.

A review of the key elements of processes demonstrates that the objective of Guiding Principal 4, balanced priorities, is implemented consistently in accordance with the PDD-1004.

\section{A-7.5 Guiding Principle Five - Identification of Safety Standards and Requirements}

Guiding Principle five, identification of safety standards and requirements, is effectively implemented. Identification of safety standards and requirements as described in detail in PDD-1004, begins with the development of a set of requirements primarily identified in laws and regulations and DOE directives, List B, contained in the INL contract (DE-AC07-05ID14517), and it also includes requirements identified in such overarching documents as the scope of work and contract clauses. These requirements form the basis for the development of work processes, guided by the ISM guiding principles and core functions that permeate the INL organization from management through the facilities and activities to the employee, with a primary focus on the employee. List B can be found on the INL intranet and includes the DOE directives that contain requirements relevant to the scope of work under the contract. In most cases, the requirements applicable to the contract are contained in a Contractor Requirements Document attached to the DOE directive.

Several improvements were made to the identification of safety standards and requirements process during FY 2011. Requirements Management for example, initiated an effort to consolidate Laboratory contract requirements into a central database. Consolidation of the requirements gives INL organizations the capability to map requirements directly to implementing documents. Other applicable methods were incorporated into the requirements management process and database. Prior to this accomplishment, 
implementing documents for each management system were identified in separate applications and documents. With this enhancement, Requirements Management can now provide the link to the implementing mechanism for each requirement and deliver the information through the Systems Integrating Management System reports, demonstrating accurate traceability of requirements implementation across management systems. Due to this consolidation of requirements, current, centralized, and easily accessible requirements implementation data are available to INL employees across the Laboratory.

After recent changes to contract requirements, INL identified the need for more in-depth, crosscutting implementation strategies. Due to the high costs and significant schedule impacts of implementing specific requirement changes, INL has adopted more comprehensive and integrated impact analysis efforts to address implementation of high impact requirements. A pilot project consisting of a crossorganizational project team was conducted to develop an implementation strategy for National Fire Protection Association (NFPA) 70E 2009, "Standard for Electrical Safety in the Workplace," and was led by the Occupational Safety and Health management system with help from INL's Project Management Office. PLN-14103, NFPA 70E 2009 Implementation Strategy and Analysis, describes the proposed strategic approach for addressing the impacts and mitigating potential risks associated with implementation of NFPA 70E 2009. It was presented to DOE-ID on November 10, 2009, and deemed a success. This pilot process resulted in the appropriate engagement of both INL and DOE-ID leadership in risk and cost/benefit decision making and engaged work planning already in place to more efficiently enable the implementation of the revised standard.

\section{A-7.6 Guiding Principle Six - Hazard Controls Tailored to Work Being Performed}

Guiding Principle six, hazard controls tailored to work being performed, is effectively implemented. The objective of hazard identification, analysis, and control is the safe accomplishment of the INL mission by eliminating or mitigating hazards to protect the workers, the public, the environment, and the INL facilities and programs.

The INL has developed a number of viable and proven mechanisms as described in detail in PDD-1004 to meet this objective. These mechanisms exist at the Laboratory, facility, and activity levels and have been tailored to the different work functions and work areas of INL. This Guiding Principle is directly related to core functions 2 and 3. See section A-4.1 for assessments and improvement actions taken in FY 2011.

\section{A-7.7 Guiding Principle Seven - Operations Authorization}

Guiding Principle seven, operations authorization, is effectively implemented. Work is authorized and performed at the INL at the Laboratory, facility, and activity level through formal processes as described in PDD-1004. The INL contract provides INL legal authority at the Laboratory level, to plan and conduct the INL work scope. Operating boundaries at the facility level are established for each facility in accordance with functional area requirements. These facility limits are identified in documents such as safety basis documents, fire hazard analysis, and project environmental hazards and controls. Limits established in these documents are evaluated as part of the project management and work control processes prior to approval of work. Accomplishing work safely at the activity level is the end result of the planning, budgeting, scheduling, analysis, evaluation, and management activities. Line management ensures the proposed activity will be conducted in compliance with facility/project requirements, such as safety basis documents, and environmental regulations and permits, by appropriately trained and qualified personnel following approved work control documents or instructions. 
While Guiding Principle 7 implementation follows a robust, effective INL process that is closely related to Guiding Principles 1 and 2, opportunities for improvement were evaluated in FY 2011 that relate to ensuring full understanding of line management, roles and responsibilities, operations authorization authority, especially when work space is shared between different organizations and management systems as discussed in section A-6.3.6.

\section{A-7.8 Guiding Principle Eight - Employee Involvement}

Guiding Principle eight, employee involvement, is effectively implemented. Employee involvement was added as an eighth guiding principle by INL to DOE's seven guiding principles. Mechanisms are in place to help ensure every employee accepts responsibility for safe mission performance. VPP is a strong component of employee involvement. INL strives to create a culture where individuals demonstrate questioning attitudes by challenging assumptions, investigating anomalies, and considering potential adverse consequences of planned actions. All employees are mindful of work conditions that may impact safety and assist each other in preventing unsafe acts or behaviors. Regardless of complexity, activities are undertaken with full understanding by each employee involved that they are individually responsible for their own safety and the safety of others involved in or affected by the activity. Personnel are qualified through training and experience to perform the assigned activity. They understand that they are required to follow established instructions or work control documents for the activity being undertaken. They also actively participate in developing and changing the instructions or work control documents they are required to follow. Personnel clearly understand that they not only have the right, but are obligated to stop work at any time if they are aware that a potentially unsafe condition exists. Some of the mechanisms that encourage employee involvement are discussed below.

\section{Safety Observations Achieve Results}

Safety Observations Achieve Results (SOAR) observations yielded unprecedented employee participation levels during the year with a 130,505 observation milestone being accomplished. SOAR is an actively caring, peer-to-peer and self-observation process that empowers employees to view their safe behaviors as well as that of their co-workers. It is a behavior-based application that allows employees to participate on a voluntary basis and focuses on safe behaviors and at-risk behaviors as well as positive reinforcement.

The essence of the SOAR process is the observation itself, and the benefit is that observers and observees participate in a process of on-the-spot awareness and critical reflection to help correct and prevent at-risk behaviors. The data derived from SOAR are not the essence of the process but a secondary benefit. For the most part, the data are positive, as the observation is an on-the-spot prevention tool. Employee Safety Teams (ESTs) can drive focused observations to address recent areas of risk (i.e., Transportation promoting bus passenger observations following curtailment and other ESTs focusing on pedestrian safety observations, and most recently cyber security observations, etc.). SOAR coaches review the data and observations looking for trends or conditions (comments provided) to be addressed by the respective and impacted EST. Due to the nature of the process, at-risk data is minimal. The EST then provides some means of awareness, action (sometimes DO ITs) or intervention if there are any trends or conditions. Similar means are provided for the INL population (refer to online safety meetings, iNotes, etc.) when crosscutting trends or conditions appear. SOAR process efforts are published on a monthly basis by each EST at their respective meetings and at the Laboratory EST meeting.

A study at the University of California at Santa Barbara (as well as follow-on cooperative research with Stanford University and the University of British Columbia) revealed that our minds wander 5.4 times in a 45-minute session even when trying to concentrate on the task at hand. Human Performance and SOAR training facilitate an understanding of this aspect of human nature and explain how influences around us can bring about such at-risk behaviors. We are able to identify and correct potential hazards in 
our behaviors during execution of work and our surroundings that we might not have otherwise recognized because of this training. Organizations such as Security, Radiological, and Cyber Security have experienced incidents associated with at-risk behaviors and have employed the SOAR process to facilitate and disseminate the appropriate behaviors by means of SOAR checklists.

SOAR is not meant to be a stand-alone process to impact safety - it is merely one option for employees to actively participate. A myriad of tools are required to further enhance our safety. Management support sustains the process for overall performance and impact, and some organizations have begun to develop management observations processes that will not only address safety and behaviors but process flow, conditions in the workplace, and efficiency.

Nonwork-related observations are also a focus as transference of awareness and learning at all times as the $24 / 7$ safety framework continues to be a focus.

Presently, over 90 checklists are available in the SOAR process.

\section{Human Performance Improvement (HPI)}

The HPI process refines human performance to enable desired outcomes by ensuring that the human performance concepts, principles, and tools are incorporated into INL procedures, processes, and daily work activities. The HPI program conducted a management assessment to assess its FY 2011 effectiveness. The assessment team determined that the implementation of human performance principles and practices at INL have been integrated throughout the site and are most evident in those organizations that are seeing the most improvements. All performance trends improved since the last assessment. In particular, the assessment determined that:

- Inclusion of human performance principles and practices in INL processes generally produces the expected result as scheduled and budgeted. The assessment has demonstrated management participation and intervention when necessary.

- Systems for assessing and evaluating hazards seem to be effective in proactively identifying issues and moving issues and problems through the present corrective action system.

- HPI reviews show an increase in manager involvement in the development and effectiveness of corrective actions, which is a key to our continued and on-going improvement processes.

Increasing the use of HPI tools and training make it likely that more employees will recognize errorlikely situations and prevent errors. The HPI program is planning to more actively promote the suite of proven HPI tools and processes, qualification programs, and personnel training and mentoring. These tools and processes have also been integrated into the safety leadership strategy. 